\title{
CO2-mitigation options for the offshore oil and gas sector
}

Nguyen, Tuong-Van; Tock, Laurence ; Breuhaus, Peter; Maréchal, François ; Elmegaard, Brian

\section{Published in:}

Applied Energy

Link to article, DOI:

10.1016/j.apenergy.2015.09.088

Publication date:

2016

Document Version

Peer reviewed version

Link back to DTU Orbit

Citation (APA):

Nguyen, T-V., Tock, L., Breuhaus, P., Maréchal, F., \& Elmegaard, B. (2016). CO -mitigation options for the offshore oil and gas sector. Applied Energy, 161, 673-694. https://doi.org/10.1016/j.apenergy.2015.09.088

\section{General rights}

Copyright and moral rights for the publications made accessible in the public portal are retained by the authors and/or other copyright owners and it is a condition of accessing publications that users recognise and abide by the legal requirements associated with these rights.

- Users may download and print one copy of any publication from the public portal for the purpose of private study or research.

- You may not further distribute the material or use it for any profit-making activity or commercial gain

- You may freely distribute the URL identifying the publication in the public portal 


\title{
$\mathrm{CO}_{2}$-mitigation options for the offshore oil and gas sector
}

\author{
Tuong-Van Nguyen ${ }^{\mathrm{a}, \mathrm{b}, *}$, Laurence Tock $^{\mathrm{b}}$, Peter Breuhaus $^{\mathrm{c}}$, François Maréchal $^{\mathrm{b}}$, Brian Elmegaard $^{\mathrm{a}}$ \\ ${ }^{a}$ Section of Thermal Energy, Department of Mechanical Engineering, Technical University of Denmark, \\ Building 403, Nils Koppels Allé, 2800 Kongens Lyngby, Denmark \\ ${ }^{b}$ Industrial Process and Energy Systems Engineering Laboratory, École Polytechnique Fédérale de Lausanne, \\ Station postale 9, 1015 Lausanne, Switzerland \\ ${ }^{c}$ Department of Energy, International Research Institute of Stavanger, \\ Professor Olav Hanssens vei 15, 4021 Stavanger, Norway
}

\begin{abstract}
The offshore extraction of oil and gas is an energy-intensive process leading to the production of $\mathrm{CO}_{2}$ and methane, discharged into the atmosphere, and of chemicals, rejected into the sea. The taxation of these emissions, in Norway, has encouraged the development of more energy-efficient and environmental-friendly solutions, of which three are assessed in this paper: (i) the implementation of waste heat recovery, (ii) the installation of a $\mathrm{CO}_{2}$-capture unit and (iii) the platform electrification. A North Sea platform is taken as case study, and these three options are modelled, analysed and compared, using thermodynamic, economic and environmental indicators. The results indicate the benefits of all these options, as the total $\mathrm{CO}_{2}$-emissions can be reduced by more than $15 \%$ in all cases, while the avoidance costs vary widely and are highly sensitive to the natural gas price and $\mathrm{CO}_{2}$-tax.
\end{abstract}

\section{Introduction}

The extraction and processing of oil and gas on offshore petroleum fields was responsible for up to $26 \%$ of the total $\mathrm{CO}_{2}$-emissions of Norway in 2011, and this share will likely stay significant in the coming years. These emissions are mainly caused by the combustion of natural gas on-site for power generation purposes, and they are subject to a hydrocarbon fuel tax, which has increased from 210 (\$35) [1] to 410 NOK (\$67) [2] per ton of $\mathrm{CO}_{2}$. A reduction of greenhouse gas emissions can therefore result in lower operating costs and possibly higher energy savings, and this can be achieved by (i) decreasing the energy demand of the processes implemented on the platform, (ii) increasing the efficiency of the power generation plant, (iii) implementing a carbon capture unit, or by (iv) electrifying the facility.

(i) Regarding the first possibility, many studies assess the performance of oil and gas separation plants by analysing thermodynamic inefficiencies and estimating the potentials for reducing the energy and exergy losses.

*Principal corresponding author. Tel.: +4545254129

Email address: tungu@mek.dtu.dk, tuong-van.nguyen@epfl.ch (Tuong-Van Nguyen) 
de Oliveira Jr. and Van Hombeeck [3] conducted the first exergy analysis of a Brazilian oil and gas platform, and they showed that most inefficiencies are related to the petroleum heating and separation steps. Voldsund et al. [4] assessed the performance of a Norwegian offshore facility and pinpointed the gas compression process as the most exergy-destroying process. Nguyen et al. [5] conducted a similar analysis on another plant, located in the Norwegian Continental Shelf, and the same conclusions were drawn. These authors extended later their analysis to two other actual cases [6]. Their findings highlighted the impacts of different field properties and export specifications on the power, heating and cooling demands. The more recent work of Nguyen et al. [7] suggested that promoting process integration on oil and gas facilities would be an effective measure for improving their energy performance, and this was illustrated by comparing different facility configurations.

(ii) The second possibility has been discussed in several recent works, with the analysis of SRC (steam Rankine cycle) and ORC (organic Rankine cycle).

Kloster et al. [8] argued that the implementation of steam cycles is technically feasible and would result in a strong decrease of the $\mathrm{CO}_{2}$-emissions, as proven with three case studies located in the North Sea [9]. In addition, Nord et al. [10] pinpointed many practical challenges, since there are stringent constraints with regards to the maximum weight and space allowable on-site. Pierobon et al. [11] proposed a methodology for designing ORCs for offshore applications. Barrera et al. [12] evaluated the influence of different field conditions, such as the gas-to-oil ratio, on the design of an optimum ORC. These studies lack a systematic approach: they investigate, for example, the implementation of a waste heat recovery cycle offshore and present an optimisation of these systems with regards to weight, efficiency and economic aspects. However, they do not take into account system integration issues - very little attention is given on the interactions between the power and processing plants, and on the ways to actually improve the performance of the overall system. This may result in sub-optimum solutions, as illustrated with the case of SRCs [13].

(iii) The third possibility, which is to integrate a CCS (carbon capture and storage) process has been only discussed in a couple of works.

For example, the study of Sánchez and de Oliveira [14] proved that the integration of $\mathrm{CO}_{2}$-capture, offshore, with monoethanolamine, is technically feasible, at the expense of a significant energy penalty.

(iv) Last but not least, the fourth possibility consists of electrifying the platform.

This can be achieved by connecting it to the onshore electric grid [15] or to offshore wind power facilities [16]. Offshore electrification is claimed to present several technical and operational benefits, such as higher facility availability, lower maintenance costs, and higher system efficiency, at the expense 
of high investment costs. At present, a few offshore platforms located in the North and Norwegian Seas are electrified, and new projects on the electrification of other ones are ongoing.

At the knowledge of the authors, all these studies focus on a single mean to reduce $\mathrm{CO}_{2}$-emissions (i.e. waste heat recovery, $\mathrm{CO}_{2}$-capture, electrification) in the oil and gas offshore sector, but none actually compares them, and none evaluates each option considering process, thermodynamic, economic and environmental aspects.

The present work aims at addressing these gaps. The novelty of the present work is to compare all the above-mentioned means of reducing $\mathrm{CO}_{2}$-emissions, by modelling at first each option, then evaluating the associated costs and environmental impacts, and finally investigating which process parameters and economic factors play an importance. The objectives are therefore to (i) evaluate the prospects for integrating $\mathrm{CO}_{2}$-mitigation processes (waste heat recovery, $\mathrm{CO}_{2}$-capture, and electrification) on an existing oil and gas platform, (ii) assess their thermo-environomic (i.e. thermodynamic, economic and environmental) performance, (iii) and identify the possible trade-offs, by performing multi-objective optimisations.

\section{Methodology}

The methodology followed in this work has been extensively described in Bolliger et al. [17]: it builds on a combination of flowsheeting techniques, energy integration models, economic evaluations using the correlations of Turton et al. [18] and a multi-objective optimisation routine [19], based on a genetic algorithm

(Figure 1). The aims of the present methodology are to:

- extract, analyse and optimise simultaneously various process designs considering process, energetic, economic and environmental indicators;

- develop flow-sheets that represent appropriately the physical and chemical processes taking place in oil and gas processes, as well as in $\mathrm{CO}_{2}$-capture systems;

- pinpoint possible systems improvements by process and energy integration;

- perform consistent economic evaluations based on cost correlations;

- assess the environmental impacts of integrating $\mathrm{CO}_{2}$-capture processes in offshore conditions;

- identify the most optimal configurations by multi-objective optimisations and comparing systematically $\mathrm{CO}_{2}$-mitigation processes.

This framework may be divided into three steps: modelling, analysis and optimisation. The models are of two types: mathematical models, which describe the physical behaviour of the system under interest, and thermo-economic models, which evaluate the thermodynamic, economic and environmental performance of 
that system. The mathematical models are built on data collection provided by the project partners and on information from the literature. They are embedded in a system superstructure in a way to include all possible options and connections between different sub-systems.

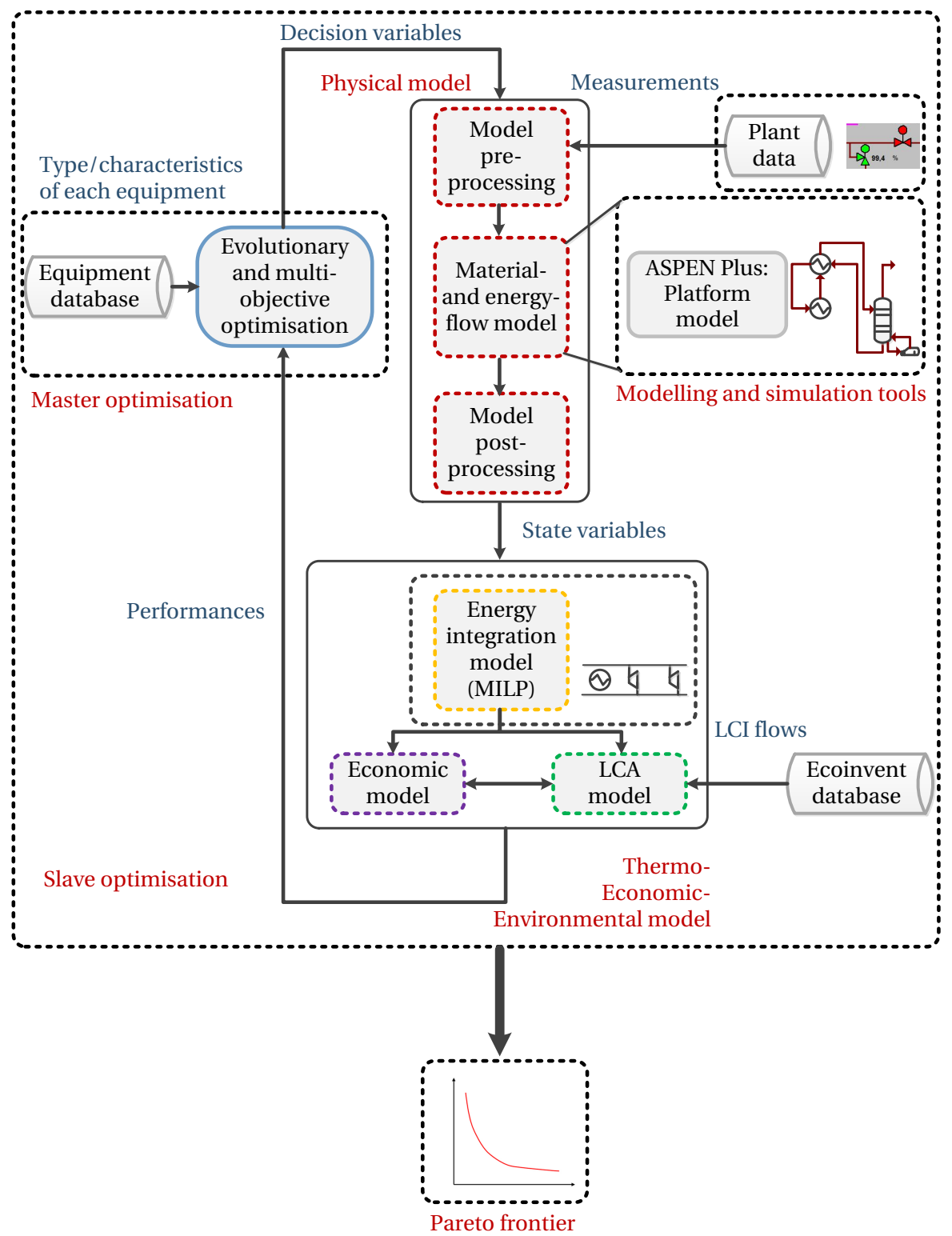

Figure 1: Illustration of the methodology and computational framework used for the modelling, simulation and optimisation of offshore platforms with $\mathrm{CO}_{2}$-mitigation. 
Each mathematical model follows a calling sequence in three phases: pre-processing, simulation and post-processing. The pre-processing phase selects the process model of interest, collects and transfers the decision variables. The simulation phase runs the mathematical model, computing the material and energy flows using a flowsheeting software such as Aspen Plus [20]. In the case of an offshore platform, the main thermodynamic relations describing the energy and exergy balances are presented in Appendix A. The post-processing phase extracts the information of interest from the process models, such as temperatures, pressures and state variables, and sends it to the thermo-economic models. The information transfer from one phase or model to another is handled by using a Matlab-based platform named OSMOSE.

The thermodynamic performance of the system of interest can now be evaluated in the thermoeconomicenvironmental analysis models, since all the material flows and energy requirements have been computed. Energy, Pinch, Total Site and exergy analyses are performed. The reader is referred to the textbooks and articles of Linnhoff [21] for an overview of the basics of the Pinch analysis technique, of Smith [22] for an overview of the Total Site Analysis method, and of Kotas [23] for the energy and exergy assessment methods.

The thermoeconomicenvironmental analysis models include an energy-integration model, which builds on the use of the Pinch analysis technique [24]. The aim is to minimise the external energy demands and associated operating costs, and the model is formulated as a MILP (Mixed Integer Linear Programming) problem, whose formulation is presented in Appendix B.

The economic performance is then evaluated by performing cost estimations using, among others, the correlations of Turton et al. [18]. The economic model is discussed in Appendix C. The environmental impacts are estimated by conducting a life cycle assessment, following the approach of Gerber et al. [25]. The impacts are normalised with regards to the FU (functional unit) of this system, which is here taken as $1 \mathrm{Sm}^{3}$ of oil equivalent exported to the shore. The LCI (life cycle inventory) flows, e.g. the elementary flows associated with, for instance, the pollutant emissions during operation, are calculated and their impacts are computed from the Ecoinvent ${ }^{\circledR}$ database [26].

In the next step, multi-objective optimisations are conducted to define the system configurations that, for example, simultaneously minimise the economic costs or environmental impacts, while maximising the internal heat recovery and the thermodynamic performance [27]. The optimisation problem is based on the decision variables used in the pre-processing phase of the mathematical models, and on performance indicators calculated in the thermoeconomicenvironmental analysis models. For each evaluation, the performance of the simulated system is re-assessed, and an evolutionary algorithm is used to emulate the values of the decision variables. The latter are then re-sent through the pre-processing phase, closing the evaluation loop.

This mathematical problem includes discrete and continuous variables, as well as linear and non-linear relationships among them. It is therefore a MINLP (Mixed Integer Non-Linear Programming) problem, decomposed in this work into two sub-problems, namely a master and a slave problem. As this optimisation includes possibly conflicting objectives, the results do not consist of a single solution but as a set of Pareto- 
optimal ones.

\section{System description}

\subsection{Oil and gas platforms}

Oil and gas platforms present similar structural designs, but they process petroleum with different characteristics (e.g. viscosity) and operate on fields with different properties (e.g. temperature, pressure, water- and gas-to-oil ratios). An oil and gas facility can be divided into two main sub-systems: a processing plant, where oil, gas and water are separated and treated, before being exported to the shore or rejected to the environment; and an utility plant, where the power and heat required for driving the separation and compression processes are produced.

The platform taken as case study exploits an oil field in the Norwegian Continental Shelf region, approaching its end-life. In the last decade, the oil and gas production has declined, while the water extraction has increased, resulting in a feed water cut over $85-90 \mathrm{~mol} \%$ for most wells. The process flow diagram, together with additional data, is given in Appendix D. The facility is characterised by a power demand of about $19 \mathrm{MW}$, a heating demand smaller than $5 \mathrm{MW}$ and a cooling demand greater than $30 \mathrm{MW}$, which is met by processing more than $2000 \mathrm{~m}^{3} / \mathrm{h}$ of seawater at about $8^{\circ} \mathrm{C}$ and lifted on-site. The Pinch point of the overall facility is located at about $150{ }^{\circ} \mathrm{C}$, illustrating that most heat discharged to the environment is at low (under $100{ }^{\circ} \mathrm{C}$ ) temperatures. The heating demand takes place between 150 and $230{ }^{\circ} \mathrm{C}$ and is satisfied by recovering heat from the exhaust gases at about $330^{\circ} \mathrm{C}$. The thermal efficiency of the gas turbines varies between $23 \%$ (current operating point) to $34 \%$ (nominal design point), and the energy intensity, on the higher heating value basis, amounts to $4.6 \%$. The total daily $\mathrm{CO}_{2}$-emissions produced locally reach about 450-460 tons, of which more than $90 \%$ are correspond to the operation of the gas turbines.

\section{2. $\mathrm{CO}_{2}$-mitigation}

\subsubsection{Superstructure}

The different technological options that can be implemented to reduce the $\mathrm{CO}_{2}$-emissions of the oil and gas plant (waste heat recovery and $\mathrm{CO}_{2}$-capture) are investigated and included in a general system superstructure (Figure 2). The integration of $\mathrm{CO}_{2}$-capture on oil and gas platforms is not common, as it faces several technical and economical challenges. $\mathrm{CO}_{2}$-separation with acid gas (i.e. $\mathrm{CO}_{2}$ and $\mathrm{H}_{2} \mathrm{~S}$ ) removal is a mature technology and is widely applied in hydrocarbon processing industries such as refineries. It is also a common process for purifying hydrogen after steam reforming processes, such as in integrated gasification combined cycle plants. Most applications are nevertheless onshore, and $\mathrm{CO}_{2}$-separation offshore is limited to natural gas platforms if the initial $\mathrm{CO}_{2}$-content is considered too high for export. 


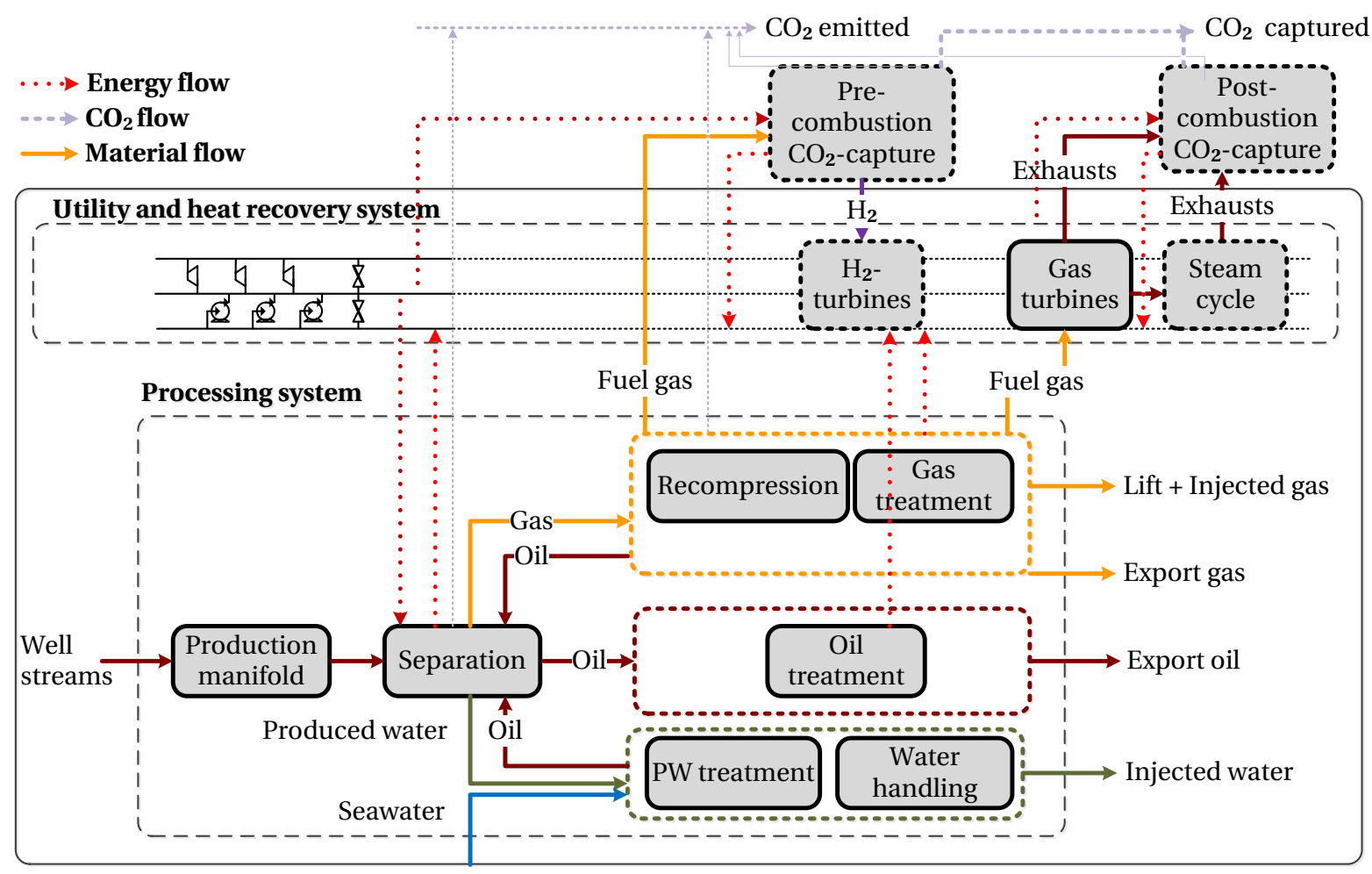

Figure 2: A generalised superstructure for integration of $\mathrm{CO}_{2}$-capture on offshore platforms.

\subsubsection{Waste heat recovery}

Heat-to-power technologies are necessary to convert waste heat into power, of which the steam Rankine cycles are the predominant ones. Such technologies are mature for onshore applications, but the integration of these technologies offshore was performed only on three facilities [8] and has faced several practical challenges [28]. Organic Rankine and Kalina cycles are not considered in this study, as they have never been demonstrated in offshore applications and/or are not widely implemented. Different scenarios for the integration of steam networks can be considered, which differ (i) by the selection of the cooling utility (water and air), (ii) by the recovery of waste heat from either one or two gas turbines, (iii) the possible use of an intermediary heating loop. The details are presented in a previous work of the authors [13].

\subsection{3. $\mathrm{CO}_{2}$-capture}

There exists a large variety of $\mathrm{CO}_{2}$-separation technologies (absorption, adsorption, cryogenic distillation, membrane separation), and the present work focuses on absorption technologies. Acid gases such as $\mathrm{CO}_{2}$ are bound to an organic solvent, either chemically (chemical absorption), based on the $\mathrm{CO}_{2}$-dissociation into hydrogen carbonates $\left(\mathrm{HCO}_{3}^{-}\right)$, or physically (physical absorption), based on the solubility differences of $\mathrm{CO}_{2}$ in the feed gas and the liquid solvent [29]. Chemical absorption with alkanoamines such as monoethanolamine 
(MEA) is preferred for treatment of acid gases with low $\mathrm{CO}_{2}$ partial pressures [30]. Chemical absorption with alkanoamines such as triethanolamine (TEA), or physical absorption with methanol (MeOH - Rectisol $\left.{ }^{\circledR}\right)$ and mixtures of polyethylene glycol esters (DEPG - Selexol $\left.{ }^{\circledR}\right)$ are preferred for high $\mathrm{CO}_{2}$ partial pressures ( $\geq 7$ bar) [29]. The $\mathrm{CO}_{2}$-separation process takes place in two main columns: an absorption column, in which the solvent circulates at counter-current of the feed gas, removing $\mathrm{CO}_{2}$, and a regeneration one, in which $\mathrm{CO}_{2}$ is recovered at high purity, generally by heating up or depressurising the solvent- $\mathrm{CO}_{2}$-mixture.

There exist different pathways of $\mathrm{CO}_{2}$-capture [31] based on these separation technologies:

- pre-combustion;

The term pre-combustion $\mathrm{CO}_{2}$-capture refers to the $\mathrm{CO}_{2}$-removal from carbonaceous fuels before combustion, by, for instance, converting the primary fuel into hydrogen and $\mathrm{CO}_{2}$ [32]. Natural gas is first converted into a synthesis gas with carbon monoxide, hydrogen, water and $\mathrm{CO}_{2}$, by partial oxidation, steam reforming, auto-thermal reforming, which is a combination of the two previous paths, or cracking [33]. $\mathrm{CO}_{2}$ at high partial pressure is then separated from the synthesis gas by physical (methanol or DEPG) or chemical (TEA) absorption [34].

The major challenges encountered with these technologies are namely their high investment costs, their applicability to new plants only, and the difficulties associated with hydrogen combustion (e.g. higher radiation share in the heat transfer to the cooled components and different fluid properties). The first hydrogen-fired gas turbines will likely run on hydrogen combustion with air, as the production of pure oxygen is costly and hydrogen premixed combustion is challenging. With some exceptions, the current turbine materials cannot withstand temperatures above $1500^{\circ} \mathrm{C}$ [35]. Other issues that may be encountered are the flame stability and the production of nitrogen oxides, and research on these topics is currently on-going [36].

- oxy-combustion;

- post-combustion.

The term post-combustion $\mathrm{CO}_{2}$-capture refers to the removal of $\mathrm{CO}_{2}$ from the flue gases of a power plant (e.g. coal- or gas-fired), i.e. after the combustion process. At the difference of the exhausts from coal-fired plants, which have a high $\mathrm{CO}_{2}$-concentration, the exhausts from a gas turbine have a $\mathrm{CO}_{2}$-concentration of only 3 to $5 \%$, as well as a relatively low pressure (near atmospheric), and chemical absorption with MEA is preferred.

The rest of this work focuses on the pre- and post-combustion paths, as the oxy-combustion one is the least mature and requires, by definition, production of pure oxygen, which is generally done by cryogenic air separation at very low temperatures. 


\subsubsection{Electrification}

The term electrification refers to the supply of electricity from shore to offshore oil and gas installations. A platform can be partly or fully electrified, depending on whether the heating demand, if any, is satisfied by electric heaters or by gas-fired burners, and on part of or all the electrical consumption is supplied by landbased electricity (Figure 3). The distance from the shore has an impact on the economic cost of electrifying a platform. However, no numbers could be found in the literature, and the analysis of current studies shows that electrification may be viable for short and medium distances.

\section{Electrification}

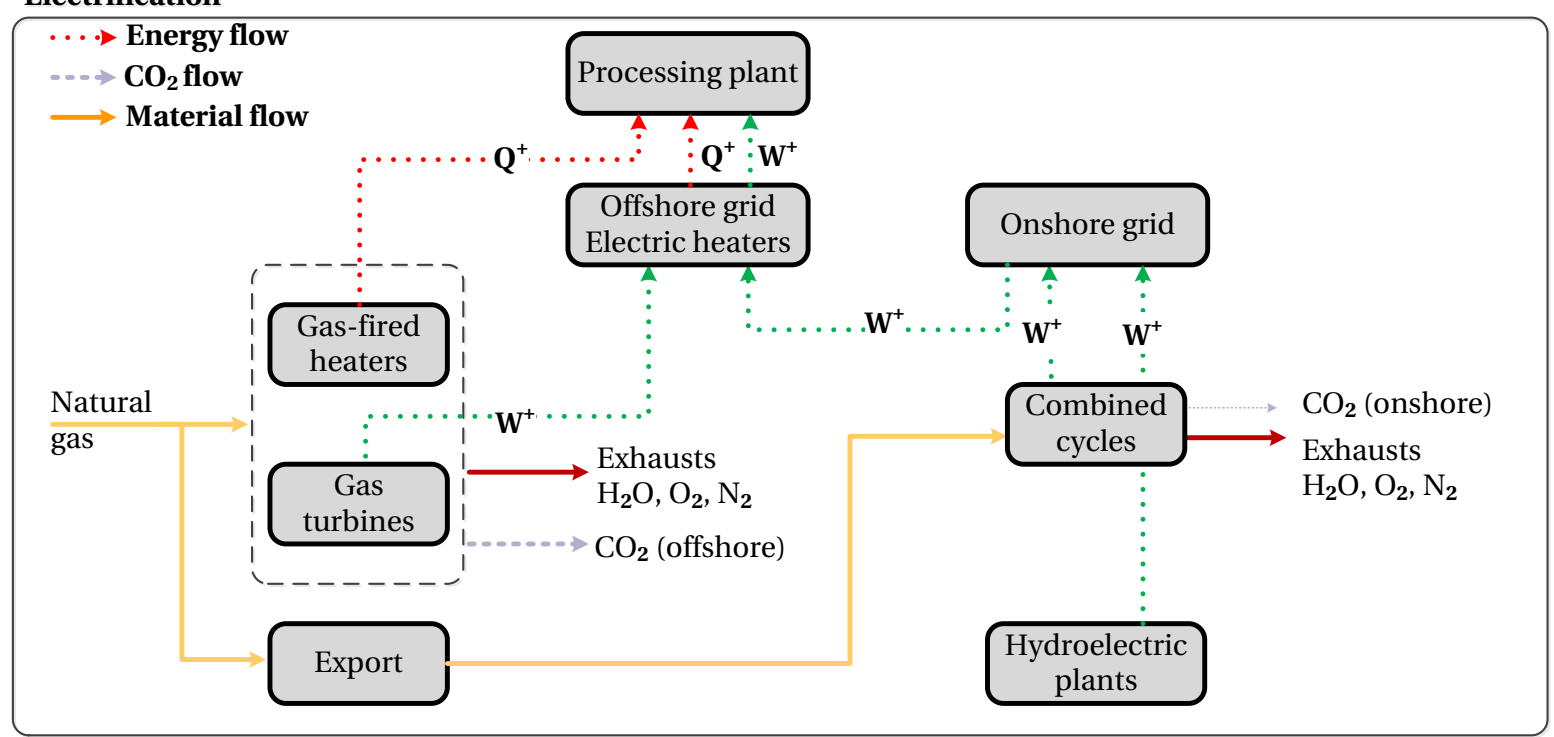

Figure 3: A generalised superstructure for integration of electrification on offshore platforms.

- internal heat recovery between process streams; 
- electric heaters fuelled with on- or offshore power;

- heat pumps driven by on- or offshore power;

- burners and furnaces fuelled by natural gas.

Two electrification scenarios are considered in the rest of this study, referred as Scenario 1, where all the power demand is satisfied with power from the mainland, but the heating demand is ensured by natural gas combustion in heaters and furnaces. This scenario is likely for offshore platforms where recovering heat from the gas turbine exhausts is not sufficient, if the oil is too viscous or heavy, or if the feed petroleum has a low temperature. In Scenario 2, it is assumed that the heating demand is satisfied by electric heating, which is likely if the heating demand is minor, and all power is supplied from shore.

Different electrification sources can be considered, depending on the case study and country of interest. However, only the hydro- and combined cycle power plants options are assessed in this work, as these possibilities are the ones that are mostly discussed in the literature. Those are the most relevant one in the case of Norway, where the average electrical supply is mainly ensured by hydro-electric dams, and the marginal one builds on the import of electricity from e.g. Denmark and Germany, where state-of-the-art gas-fired power plants are implemented. The type of electrical production is relevant when performing an environmental assessment of the different electrification options. A given solution may correspond to smaller local emissions (site-scale) but greater global ones (country-scale).

\subsubsection{Practical limitations}

There are stringent limitations on oil and gas platforms with regards to the maximum space or weight tolerable on-site, and system layouts with low equipment inventory may therefore be preferred to more complex configurations. This limits the maximum efficiency of a waste heat recovery system and the $\mathrm{CO}_{2}-$ separation potential of a $\mathrm{CO}_{2}$-capture plant. For these reasons, only 'simple' waste heat recovery cycles, built downstream the gas turbines, without extraction, and without supercritical fluids, are considered in this work. The implementation of organic cycles based on $\mathrm{CO}_{2}$ or alkanes (e.g. ethane and propane) for recovering heat from the gas compression process is not analysed.

As processes with low volume may be favoured, the integration of pre-combustion $\mathrm{CO}_{2}$-capture systems may be relevant for future offshore platforms. The volume flow rate of the fuel gases is smaller than in post-combustion plants, implying that the power generation system would be more compact. Only the design set-ups with low equipment inventory are investigated, i.e. with one absorber and a scrubber, with solely two pressure levels. In addition, there may be a need for a back-up power system or storage on-site to compensate for possible failures of the electrical grid if the platform is directly connected to it. 


\subsection{Process modelling}

The models of the oil and gas platform and of the $\mathrm{CO}_{2}$-capture by monoethanolamine are developed using the commercial flowsheeting software Aspen Plus ${ }^{\circledR}$ version 7.2 [20]. The modelling details of the steam network, with the corresponding decision variables, are presented in Nguyen et al. [5] (production levels, cooling and heating sources), and in Tock et al. [30] for the chemical absorption process $\left(\mathrm{CO}_{2}\right.$-loading, absorption and regeneration temperatures and pressures).

The gas turbines are simulated based on the work of Pierobon et al. [37]: the part-load behaviour is considered to predict the $\mathrm{CO}_{2}$-emissions along a year of operation, taking the SGT-500 gas turbine as case study. The model of the $\mathrm{CO}_{2}$-capture units with monoethanolamine is developed using the commercial flowsheeting software Aspen Plus ${ }^{\circledR}$ version 7.2 [20], based on the electrolyte NRTL method [38] for the liquid phase and the Redlich-Kwong [39] EOS (equation of state) for the vapour phase. The models of the physical absorption units are developed using the Perturbed-Chain Statistical Associating Fluid Theory EOS [40].

\section{System performance}

\subsection{Performance indicators}

The system performance can be evaluated by a large variety of thermodynamic and economic parameters, and this study focuses on:

- the energy efficiency of the cogeneration plant $\eta$, on a higher heating value $\left(\Delta h^{0}\right)$ basis;

$$
\eta_{\mathrm{CC}}=\frac{\dot{Q}^{-}+\dot{W}^{-}}{\Delta h_{\mathrm{FG}}^{0} \cdot \dot{m}_{\mathrm{FG}}^{+}}
$$

where $\dot{Q}$ and $\dot{W}$ represent the energy transfers with heat and power. The superscripts ${ }^{+}$and ${ }^{-}$denote the input and output flows. This definition considers that the heat output is useful, as it is the case for a combined cycle with heat extraction, i.e. for a combined heat and power utility plant.

- the exergy efficiency of this plant $\varepsilon$, based on a dead state of $8^{\circ} \mathrm{C}$ and $1 \mathrm{~atm}$, as these are the average air conditions in the North Sea;

$$
\varepsilon_{\mathrm{CC}}=\frac{\dot{E}_{\mathrm{Q}}^{-}+\dot{E}_{\mathrm{W}}^{-}}{\Delta k_{\mathrm{FG}}^{0} \cdot \dot{m}_{\mathrm{FG}}^{+}}
$$

where $\dot{E}_{\mathrm{Q}}$ and $\dot{E}_{\mathrm{W}}$ represent the exergy transfers with heat and power, and $\Delta h^{0}$ the exergy content of the fuel gas. 
- the grassroot costs $C_{\mathrm{gr}}$ of the $\mathrm{CO}_{2}$-capture or waste heat recovery unit;

A precise analysis of the grassroot costs of a $\mathrm{CO}_{2}$-capture or a waste heat recovery plant on an offshore platform is difficult because of (i) the very few, if none, studies on this topic, as well as the absence of case studies, (ii) the lack of knowledge on the necessary space and associated cost for installing the equipment items, (iii) the different approaches and cost correlations for evaluating the economics of a chemical or physical absorption plant.

Discussions with process and design engineers of offshore platforms stressed these three challenges. In particular, the cost of the space required for implementing these processes is expected to vary greatly from one platform to another, depending on the actual configuration of the platform. On the one hand, a well-design steam Rankine cycle may have a power capacity as high as each gas turbine installed on-site. In this case, this waste recovery unit could replace one of the gas turbines, and no additional space would be required. On the other hand, it is necessary to have redundant equipment to prevent system failures and avoid the resulting economic losses associated with a shut-down of the processing plant.

- the relative variation of natural gas $\delta_{\mathrm{NG}}$ exported to the shore (increase or decrease);

- the reduction of $\mathrm{CO}_{2}$-emissions $\delta_{C_{2}}$ caused by the decrease of fuel gas consumption and/or the possible integration of a $\mathrm{CO}_{2}$-mitigation plant;

- the changes in operating $\operatorname{costs} C_{\mathrm{op}}$;

The changes in operating costs are related to (i) the additional cooling water and pumping demands on-site for the steam condensation, (ii) the maintenance costs of the additional equipment, (iii) the money savings with the reductions of $\mathrm{CO}_{2}$-taxes, (iv) the money earnings with the increases of gas sales, and (v) the make-up of monoethanolamine, methanol and DEPG because of degradation issues and losses.

An accurate calculation of the system operating costs would require to know the economic value of the exported gas. However, the latter cannot be estimated accurately, because the gas is sent through the Åsgard pipeline system, where it is mixed with natural gas from the other petroleum fields located in the northern part of the North Sea. These hydrocarbon flows have very different chemical compositions and physical properties, and they are treated in onshore plants where they are refined into a large variety of hydrocarbon products (e.g. natural gas, liquid petroleum gases, diesel, naphta, etc.).

Calculating a precise economic value of a single natural gas stream is therefore infeasible, as this would require (i) the measurements of the exact flow rates and compositions of the gas streams from each offshore facility, and these flows vary significantly with time, and (ii) a forecast of the variations of the 
natural gas prices on the market, for different countries. On the contrary, the relative variation of the export gas flow $\delta_{\mathrm{NG}}$ is a clearer performance indicator, as it depends solely on the facility under study. Finally, it is assumed that the integration of these additional processes does neither result in an increase of the number of operators, nor in a higher operator's salary. The economic performance of these processes can be assessed with regards to the potential fuel gas savings and reductions in $\mathrm{CO}_{2}$-taxes.

- the cost of $\mathrm{CO}_{2}$-avoidance $\mathrm{CAC}$, defined as the ratio of the increase in investment costs over the decrease of $\mathrm{CO}_{2}$-emissions;

$$
\mathrm{CAC}=\frac{C_{\mathrm{gr}, \mathrm{CCS}}-C_{\mathrm{gr}, \mathrm{ref}}}{\dot{m}_{\mathrm{CO}_{2}, \text { ref }}-\dot{m}_{\mathrm{CO}_{2}, \mathrm{CCS}}}
$$

- the cost of electricity COE, defined here as the levelised cost of electricity;

$$
\mathrm{COE}=\frac{\sum_{t=1}^{n}\left(C_{\mathrm{gr}}+C_{\mathrm{op}}+C_{\mathrm{mt}}+C_{\mathrm{tax}}\right)(1+r)^{-t}}{\sum_{t=1}^{n} \dot{W}_{e l}(1+r)^{-t}}
$$

Economic analyses of carbon capture units may be evaluated using either the electricity (COE) or the $\mathrm{CO}_{2}$-avoidance $(\mathrm{CAC})$ cost. The first one illustrates the cost of using the produced natural gas in the on-site gas turbines, while the second one reflects the costs of reducing the $\mathrm{CO}_{2}$ emissions. They depend on factors such as the production cost of the fuel gas, the capital costs with the well construction and the $\mathrm{CO}_{2}$-tax on the hydrocarbon production.

- the power capacity or consumption of the additional systems $\dot{W}$.

In the following economic analysis, the base value assumed for the natural gas is taken as $8.08 \$ / \mathrm{GJ}$, which corresponds to the average sales price of natural gas in Norway for the year 2010, in the case of the Statoil company [41]. The base value assumed for the $\mathrm{CO}_{2}$ tax is taken as $65 \$ / \mathrm{t}_{\mathrm{CO}_{2}}$, which corresponds to the current value in Norway for the offshore sector [2]. These estimates are used to perform the sensitivity analyses and to give some indications on the expected electricity and avoidance costs.

Other performance indicators such as the net present value and payback period provide valuable information on the economic profitability of a given investment. However, calculating these values is not relevant, as these indicators would present high inaccuracies due to the uncertainties of the capital (as reasonable information on the space cost is missing) and operating costs (since an exact estimate of the value of the exported natural gas cannot be given). 


\subsection{Multi-objective optimisation}

\subsubsection{Objective functions}

The variety of process indicators that can be derived when evaluating the performance of an oil and gas platform with $\mathrm{CO}_{2}$-mitigation shows a competition between several factors. For example, the integration of a post-combustion $\mathrm{CO}_{2}$-capture unit results in a lower energy efficiency, higher investment costs but lower $\mathrm{CO}_{2}$-emissions. The trade-off between these competing factors is assessed by performing multi-objective optimisations, applying an evolutionary algorithm. The objectives considered in the optimisation procedure are (i) the maximisation of the power capacity $\dot{W}$ or of the exergetic efficiency $\varepsilon$, (ii) the minimisation of the investment costs $C_{\text {inv }}$, and (iii) the minimisation of the $\mathrm{CO}_{2}$-emissions $\delta_{\mathrm{CO}_{2}}$.

\subsubsection{Decision variables.}

The optimal system configurations are displayed under the form of a Pareto optimal frontier, which separates the research domain into the feasible but sub-optimal solutions, the feasible and Pareto-optimum solutions, and the infeasible ones. A solution is said Pareto-optimum if a better-off with respect to one objective results in a worse-off with respect to another one. The master decision variables amount to 48, of which 18 are related to the operation of the steam cycle (e.g. pressures, temperatures, vapour fraction) and 5 to the selection of the cooling utility (e.g. process water and temperatures) and are shown in Nguyen et al. [13]. The decision variables related to the $\mathrm{CO}_{2}$-capture processes are presented in Appendix E.

\section{Performance comparison}

\subsection{Process optimisation}

\subsubsection{Pre-combustion}

The impact of pre-combustion $\mathrm{CO}_{2}$-capture technologies on the performance of the oil and gas platform and on its utility plant can be assessed by performing a multi-objective optimisation, analysing the trade-off between the exergy efficiency and the $\mathrm{CO}_{2}$-capture rate (Figure 4). For simplicity, the possibility of purifying the $\mathrm{H}_{2}$-rich fuel obtained after the $\mathrm{CO}_{2}$-capture process, by integrating pressure swing adsorption, is not investigated.

The Pareto frontiers for the different pre-combustion processes show that the integration of $\mathrm{CO}_{2}$-capture results in a lower efficiency of the power plant, because of the energy used for heating (solvent regeneration), cooling (solvent refrigeration, with physical absorption), and power $\left(\mathrm{CO}_{2}\right.$-compression and solvent pumping). Three types of configurations with pre-combustion $\mathrm{CO}_{2}$-capture are investigated: (i) a set-up without waste heat recovery $[\mathrm{n}]$; (ii) a set-up with steam Rankine cycle, where the recovered heat only comes from the exhaust gases $[\mathrm{s}]$; and (iii) a more advanced set-up, where heat can be recovered from the turbine exhausts and different sections of the offshore system [a]. 

it sets a limit on the maximum performance that could be expected.

The impact of integrating a simple steam Rankine cycle, which utilises the heat from the gas turbine exhausts only, is investigated at first. The advantage of such configuration can be visualised by the horizontal shift of the Pareto frontiers, which illustrate that the gain in exergy efficiency is about 15 to $20 \%$-points, whether physical or chemical absorption is implemented. The third set-up, which is the most complicated, leads to an increase in efficiency for all physical and chemical solvents, at the expense of a higher number of equipment items. This configuration may not be chosen in practice for offshore implementation, since the gains in efficiency and fuel savings may be judged marginal with regards to the added complexity. However,

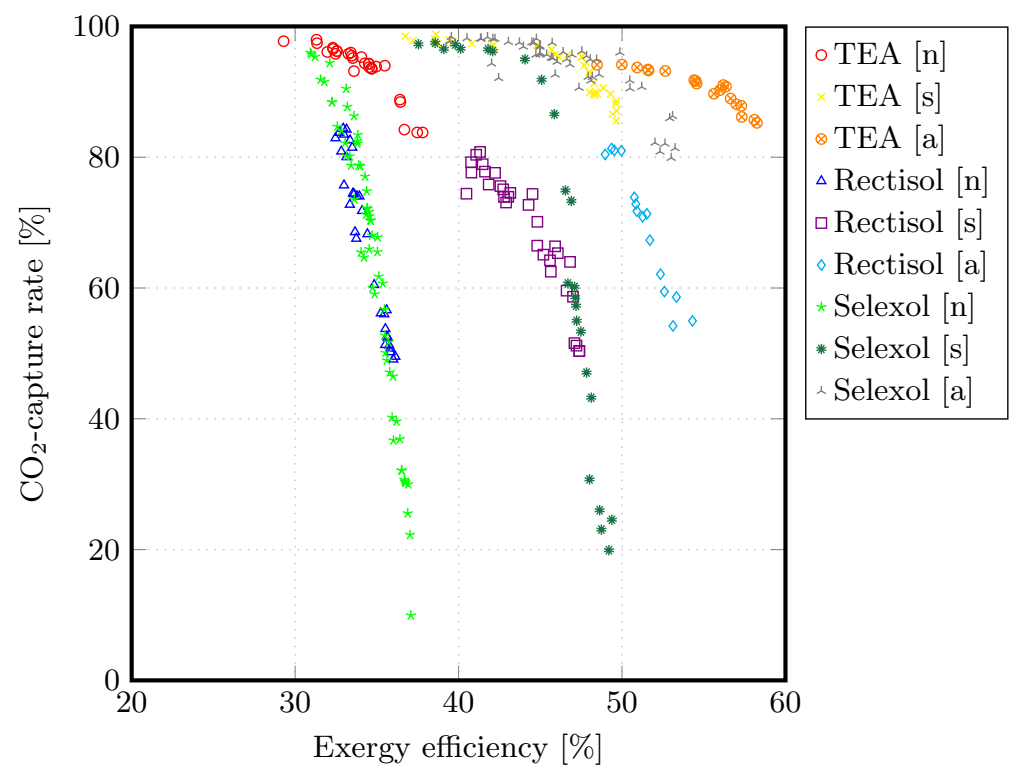

Figure 4: Pareto-optimal solutions for the site-scale integration of pre-combustion $\mathrm{CO}_{2}$-capture processes on offshore platforms: trade-off between the $\mathrm{CO}_{2}$-emissions and exergy efficiency, without steam cycle [n], with simple [s] and advanced [a] steam cycle.

\subsubsection{Post-combustion}

Similarly, the impact of post-combustion $\mathrm{CO}_{2}$-capture technologies on the performance of the oil and gas platform and on its utility plant can be evaluated by performing a multi-objective optimisation, analysing the trade-off between the increase in power generation due to the waste heat recovery cycle, and the $\mathrm{CO}_{2}$ capture rate (Figure 5). Two types of configurations are investigated: (i) a set-up with only waste heat recovery, without chemical absorption, and (ii) a set-up with post-combustion $\mathrm{CO}_{2}$-capture and a steam Rankine cycle, to visualise the energy penalty induced by the capture unit. All the configurations with post-combustion $\mathrm{CO}_{2}$-capture include a waste heat recovery cycle, because this would result in a higher thermal efficiency, and the chemical absorption of $\mathrm{CO}_{2}$ is favoured at relatively low temperatures (about 
$\left.40^{\circ} \mathrm{C}\right)$.

The maximisation of the net power capacity and the minimisation of the $\mathrm{CO}_{2}$-emissions are clearly conflicting objectives, since $\mathrm{CO}_{2}$-capture is favoured with large flows of solvent and high regeneration temperature. Significant amounts of heat from the exhaust gases are required and cannot be used in the steam network for electricity generation purposes.

The Pareto frontiers illustrate the trade-off between the increase in net power capacity and the reduction in $\mathrm{CO}_{2}$-emissions. In general, the integration of a steam network allows for a greater power production, ranging from 3 to $8 \mathrm{MW}$ at design conditions. The efficiency increases to about $35-40 \%$ when the steam cycle is run at full-load conditions, and between 28 and $33 \%$ when run for the normal operating conditions. All the optimal steam cycles consist of a single production level at a pressure between 8 and 13 bar and a condensation level below 0.5 bar. The cooling utility used in the steam condenser is the process water, i.e. the cooling water from the processing plant at about $16.5^{\circ} \mathrm{C}$. The export of natural gas to the shore increases by up to $14 \%$, and this goes along with a reduction of the $\mathrm{CO}_{2}$-emissions of up to $16-20 \%$.

If post-combustion $\mathrm{CO}_{2}$-capture is integrated, the total $\mathrm{CO}_{2}$-emissions of the platform can be reduced by up to $70 \%$, of which $\simeq 10-20 \%$-points are related to the steam network, and $\simeq 50-60 \%$-points are associated with the $\mathrm{CO}_{2}$-capture unit. The remaining $\mathrm{CO}_{2}$-emissions are caused by the flaring and secondary gas turbines on-site. The export of natural gas also increases, although the savings in fuel gas are not as significant as if only a steam cycle was integrated, because of the power demand of the $\mathrm{CO}_{2}$-sequestration unit. The $\mathrm{CO}_{2}$-capture rate varies between 83 and $93 \%$, which corresponds to a reduction of the total $\mathrm{CO}_{2}$-emissions of the platform between 55 and $70 \%$. Two configurations, which have a $\mathrm{CO}_{2}$-avoidance rate of 55 and $70 \%$, respectively, are discussed further in the energy integration and economic analyses.

\subsection{Energy integration}

\subsubsection{Pre-combustion}

The introduction of $\mathrm{CO}_{2}$-capture processes by physical absorption (Figure 6) results in different conclusions whether the Rectisol or Selexol technology is integrated. The first one systematically implies a need for cooling down the solvent (methanol) and the feed gas below ambient temperatures, increasing the electricity consumption as a refrigeration cycle should be implemented. The second one creates a refrigeration demand only if high $\mathrm{CO}_{2}$-capture rates are of interest, since the $\mathrm{CO}_{2}$-solubility in DEPG is higher at low temperatures.

In terms of power consumption, the differences between the Selexol and Rectisol processes are minor, because the synthesis gas should preferably be compressed at pressures higher than 40-50 bar in both cases to ensure high $\mathrm{CO}_{2}$-partial pressure, and the solvent pumping process has a negligible power demand in comparison to the $\mathrm{CO}_{2}$-compression. 


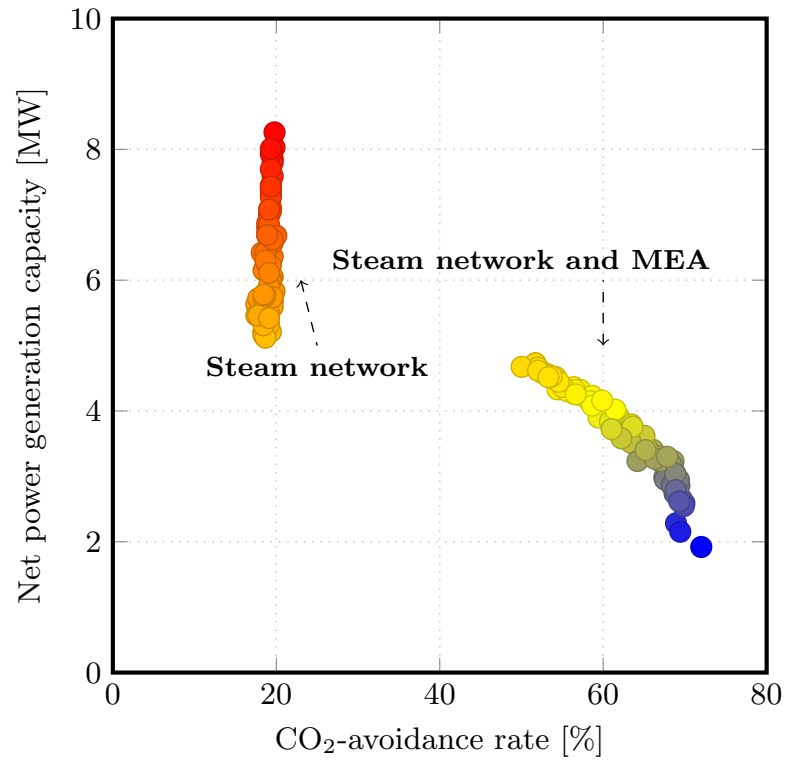

Figure 5: Pareto-optimal solutions for the site-scale integration of post-combustion $\mathrm{CO}_{2}$-capture processes on offshore platforms: trade-off between the $\mathrm{CO}_{2}$-emissions and net power capacity.
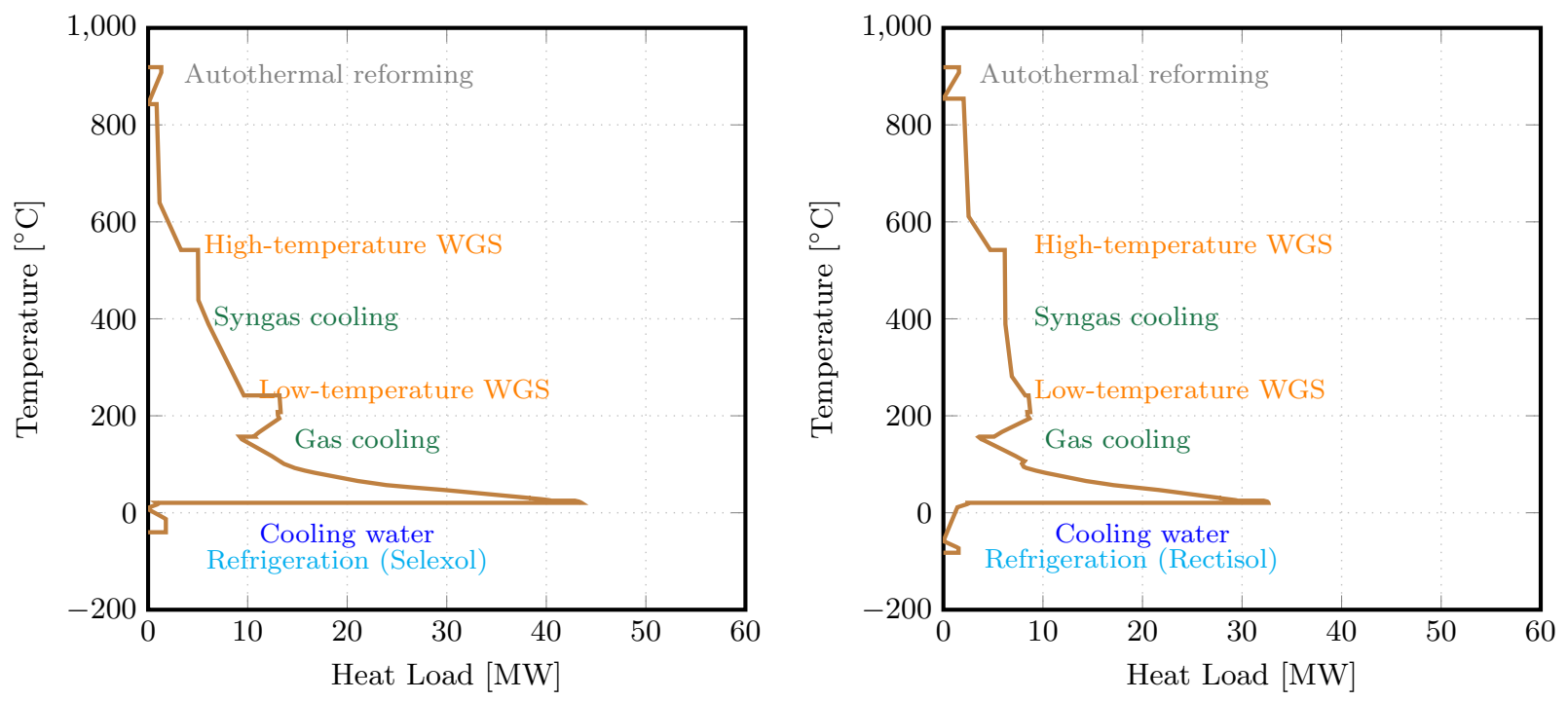

Figure 6: Balanced Composite Curves for an oil and gas platform with pre-combustion $\mathrm{CO}_{2}$-capture based on autothermal reforming and using Selexol (left) and Rectisol (right).

There is a large variety of sets of operating conditions for which a $\mathrm{CO}_{2}$-capture rate can exceed $80 \%$. It is assumed in the following examples that the $\mathrm{H}_{2}$-fuelled gas turbines replace the current SGT-500, which satisfy the baseline power demand of $16,500 \mathrm{~kW}$ and the additional power consumption, which can be split (Figure 7 and Figure 8) into the power demands of the synthesis gas preparation process, the DEPG pumping in the Selexol process, the $\mathrm{CO}_{2}$-compression and the refrigeration cycle. The same trends are found with 


\begin{tabular}{llll}
$\begin{array}{l}\text { Syngas composition } \\
(\mathrm{mol} \%)\end{array}$ & $\begin{array}{l}\text { After } \\
\text { preparation }\end{array}$ & $\begin{array}{l}\text { After } \\
\text { Selexol }\end{array}$ & \\
\cline { 1 - 3 } $\mathrm{H}_{2}$ & 54.4 & 64.4 & DEPG purity (solvent, before absorber): \\
$\mathrm{CO}$ & 1.74 & - & $97.1 \mathrm{~mol} \%$ \\
$\mathrm{CO}_{2}$ & 17.9 & 3.6 & \\
$\mathrm{~N}_{2}$ & 25.7 & 30.0 & \\
$\mathrm{H}_{2} \mathrm{O}$ & 0.2 & - & \\
\hline
\end{tabular}

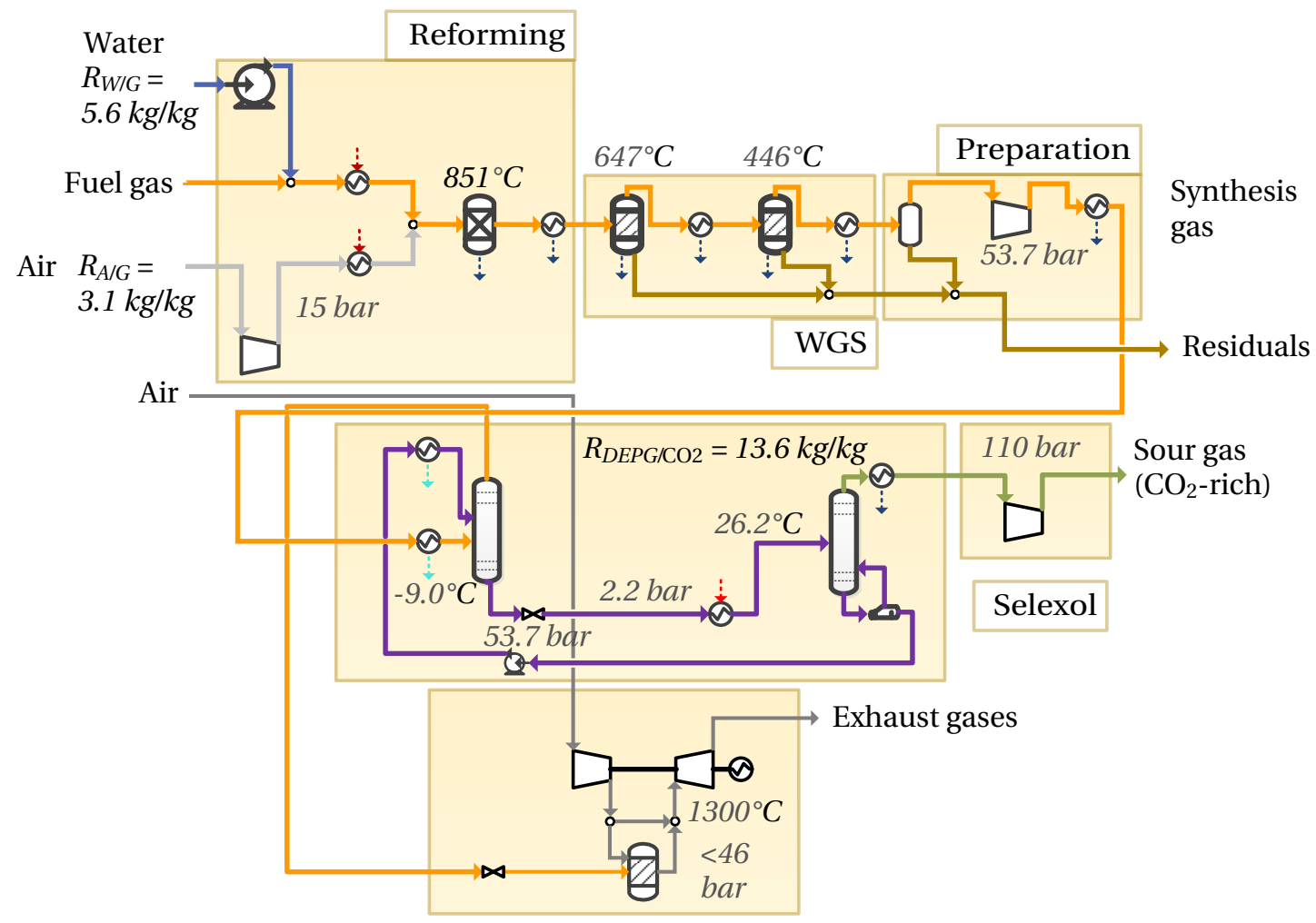

Figure 7: Example of configuration of pre-combustion $\mathrm{CO}_{2}$ capture with autothermal reforming and Selexol.

Chemical absorption processes with TEA (Figure 9) may also compete with physical absorption ones since the $\mathrm{CO}_{2}$-content may be as high as $25 \%$ for a $\mathrm{H}_{2}$-purity of $75 \%$. The heating requirements at low temperatures $\left(\leq 150^{\circ} \mathrm{C}\right)$ increase in such cases, as a chemical absorption unit is always characterised by a heating demand (Figure 10) for regenerating the amine solvent. The highest $\mathrm{H}_{2}$-purity is reached for chemical absorption with TEA along with steam methane reforming: it can exceed $90 \%$ because the produced syngas is not diluted with nitrogen, while it is limited to $65-70 \%$ if the reforming process is autothermal. The use 


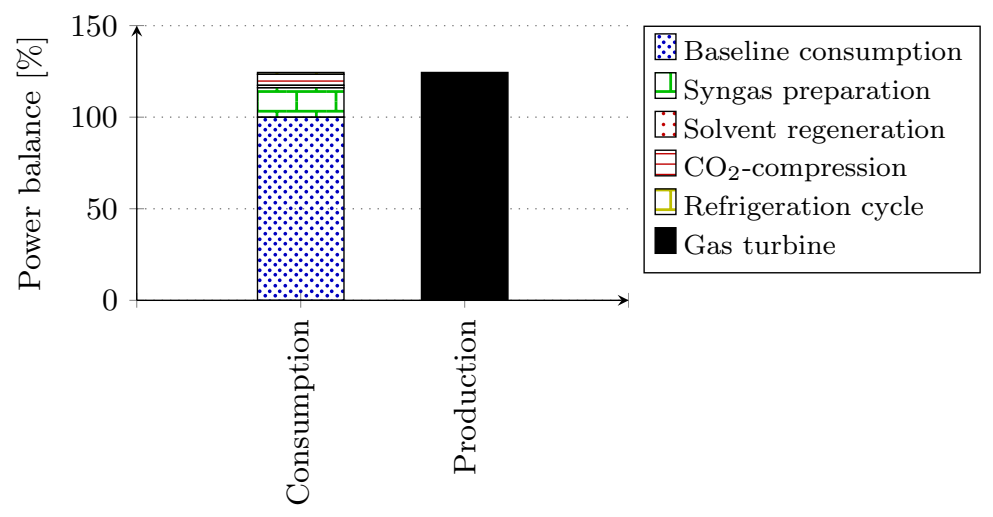

Figure 8: Power balance for an example of layout with ATR and Selexol.

of chemical absorption avoids large pressure drops in the $\mathrm{CO}_{2}$-capture unit and the need for refrigeration (Figure 11), which explains the slightly higher electrical efficiency of pre-combustion $\mathrm{CO}_{2}$-capture processes with amines in the later optimisations.

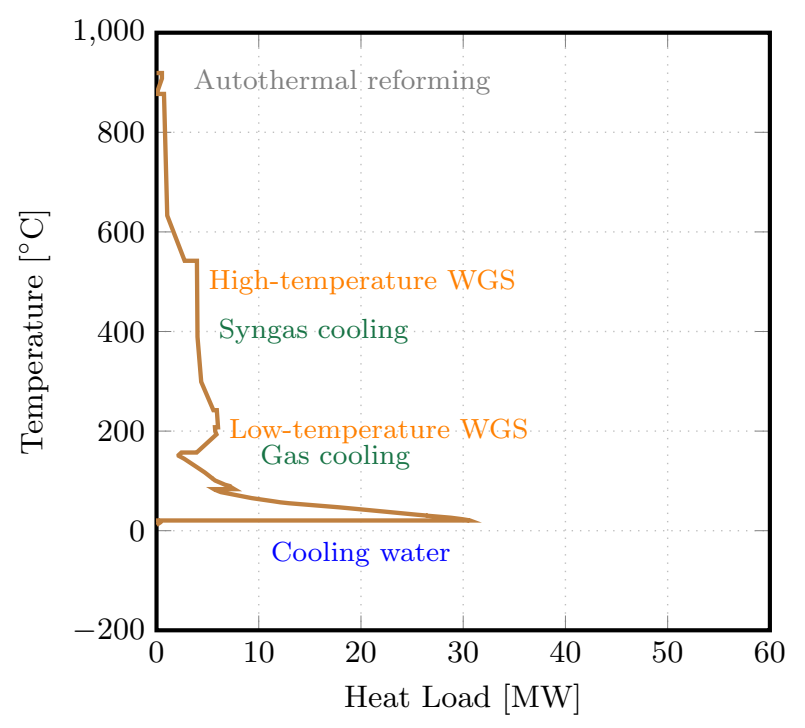

Figure 9: Balanced Composite Curve for an oil and gas platform with chemical absorption based on TEA.

Moreover, the energy required to regenerate the chemical solvent can be covered by utilising the heat from the water-gas shift reactors and syngas coolers, and that results in a smaller demand for cooling water compared to the process layouts with physical absorption. The introduction of a cogeneration utility together with a chemical absorption plant with TEA can be beneficial since it would result in a better match between the temperatures of the regeneration process and the hot utilities. However, the maximum amount of electricity that can be generated is smaller than if a physical absorption unit is integrated, because less heat is available in the temperature range of 300 to $600^{\circ} \mathrm{C}$. 
The losses of $\mathrm{CO}_{2}$ with the knock-out water are negligible in all cases, representing less than $0.5 \%$ of the total carbon entering the capture unit. However, there are losses of hydrogen with the $\mathrm{CO}_{2}$ sent to sequestration, which limit the $\mathrm{CO}_{2}$-purity to an upper bound of 96-97\%. The implementation of a 2-stage regeneration plant may be beneficial, but this configuration is not further studied in this work.

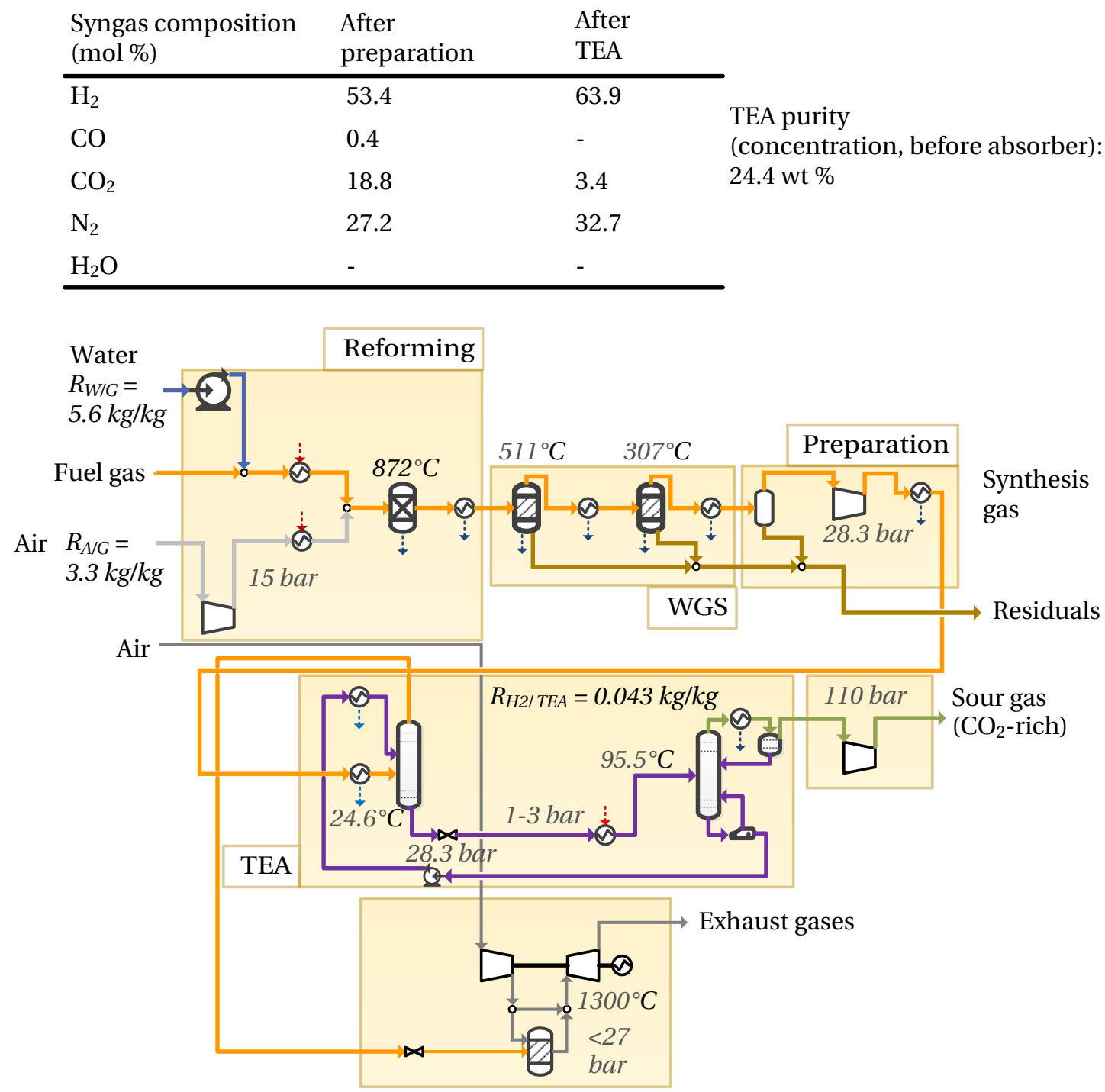

Figure 10: Example of configuration of pre-combustion $\mathrm{CO}_{2}$ capture with autothermal reforming and TEA.

\subsubsection{Post-combustion}

The installation of $\mathrm{CO}_{2}$-capture plant together with a steam cycle (Figure 12 and Figure 13) presents by far the greatest potential for $\mathrm{CO}_{2}$-reduction, but only reduces the exergy losses with the exhaust gases taking place at temperatures of 100 to $330^{\circ} \mathrm{C}$. There is a potential for recovering exergy at low temperatures, 


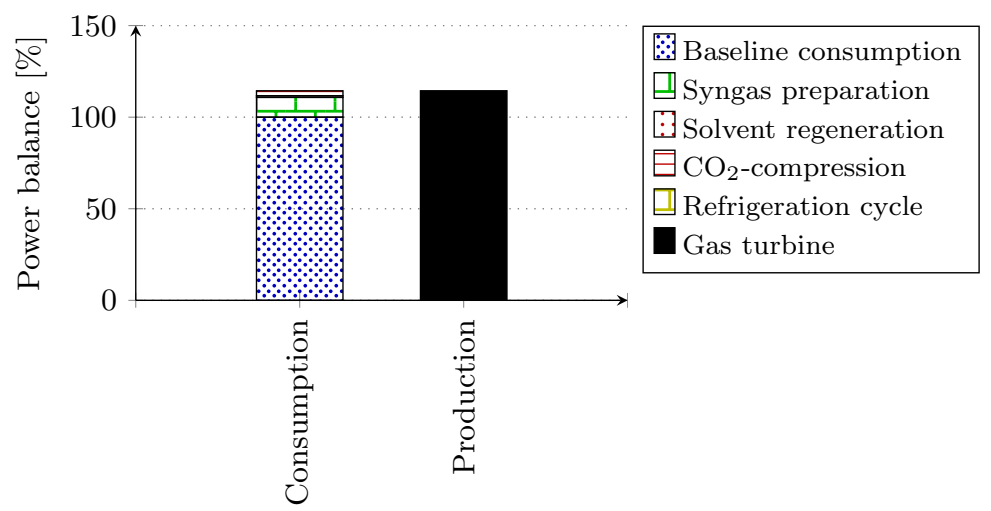

Figure 11: Power balance for an example of layout with autothermal reforming and TEA.

which is, in the proposed configurations, dissipated with cooling water, but such option may be particularly challenging. Smaller quantities of heat are dissipated into the environment with cooling water for the process designs including $\mathrm{CO}_{2}$-capture, as a fraction of the heat contained in the exhaust gases is used to regenerate MEA instead and dissipated into the environment.

The comparison of the two configurations with post-combustion capture, and a $\mathrm{CO}_{2}$-avoidance rate of 55 and $70 \%$, show that the net power capacity and $\mathrm{CO}_{2}$-capture potential are clearly conflicting objectives (Figure 14). Integrating a $\mathrm{CO}_{2}$-capture plant seems more appropriate when it is performed in conjunction with a steam cycle. The heat required in the desorption column is provided by the cooling of the exhaust gases after the gas turbines and possibly prior to the steam cycle, illustrating the synergy between the bottoming cycle and the $\mathrm{CO}_{2}$-capture plant.

The power demand at normal operating conditions increases by about $12 \%$, as a consequence of the power demand for compressing the $\mathrm{CO}_{2}$ and pumping the MEA. High $\mathrm{CO}_{2}$-capture rates result in a higher heating demand in the amine regeneration process, which should be satisfied by recovering larger amounts of waste heat from the turbine exhausts, and in a greater power consumption in the $\mathrm{CO}_{2}$-compression process. The purity of the $\mathrm{CO}_{2}$-rich stream exceeds $97 \%$ on a molar basis.

\subsubsection{Electrification}

The higher gas export results in larger cooling duty in the gas treatment section and greater power demand (Figure 15). However, platform electrification does not change significantly the temperature-enthalpy, or temperature-exergy profiles of an oil and gas platform. The exergy destruction and losses in the gas turbines are eliminated, but they are replaced with the ones related to the onshore plants (combined cycles or hydroelectric facilities), to the gas-fired heaters (if any), and to the transmission cables (power losses). The exact values of these irreversibilities are not calculated in this work, but they are expected to be smaller because of the greater efficiency of the onshore power plants and the smaller fuel gas consumption. 


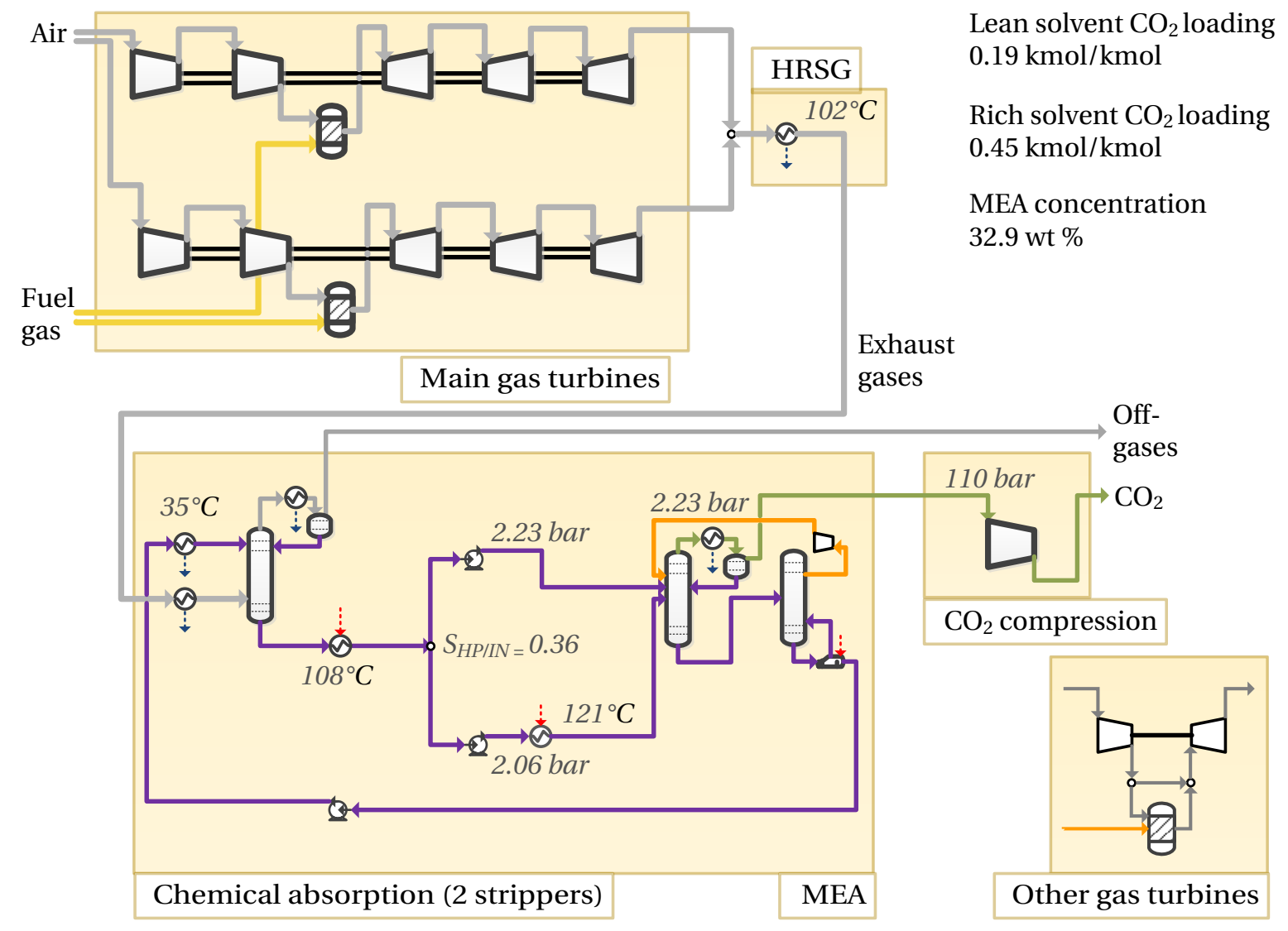

Figure 12: Example of configuration of post-combustion $\mathrm{CO}_{2}$ capture with MEA.

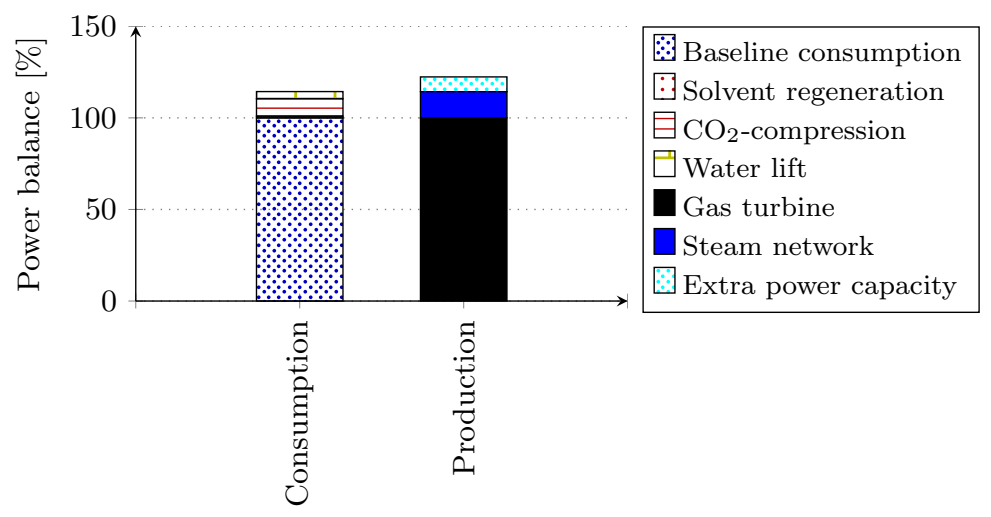

Figure 13: Power balance for an example of layout with MEA. 

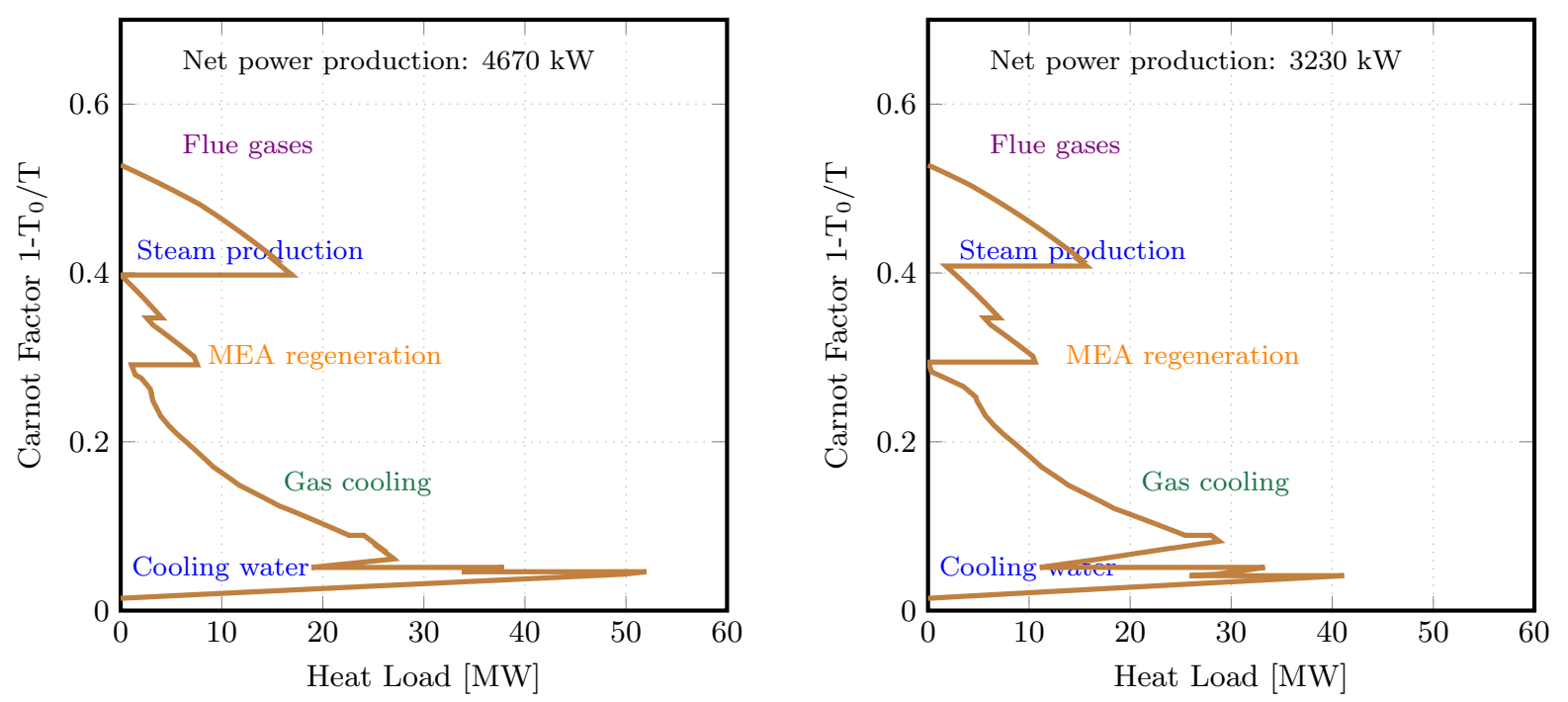

Figure 14: Balanced Grand Composite Curves, on an exergy basis, of the oil and gas platform system, including a steam Rankine and a post-combustion $\mathrm{CO}_{2}$-capture unit, with low (left) and high (right) $\mathrm{CO}_{2}$-capture rate.

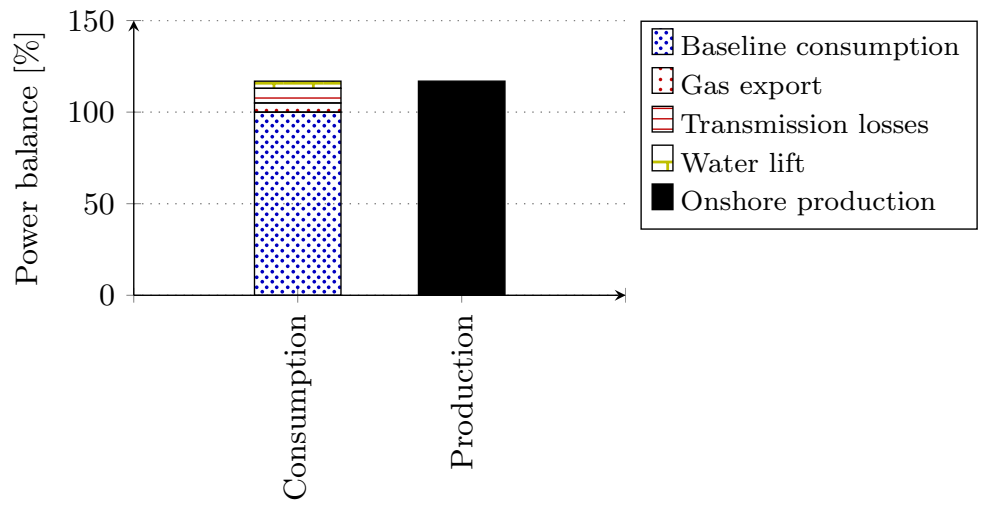

Figure 15: Power balance for an example of layout with electrification (Scenario 1).

\subsection{Economic performance}

\subsubsection{Economic build-up}

A preliminary assessment of the economic build-up of the capital costs of such plants (Figure 16) suggests that pre-combustion $\mathrm{CO}_{2}$-capture processes are more costly than post-combustion ones, which is consistent with the conclusions drawn in the literature. The additional costs, related to the initial costs of the processes installed on the Draugen platform, vary between 10 to $40 \%$ : the application of the economic correlations suggests that a configuration based on the Selexol process is the most costly, but the differences with the other system layouts are within the range of uncertainty given in Turton et al. [18]. 


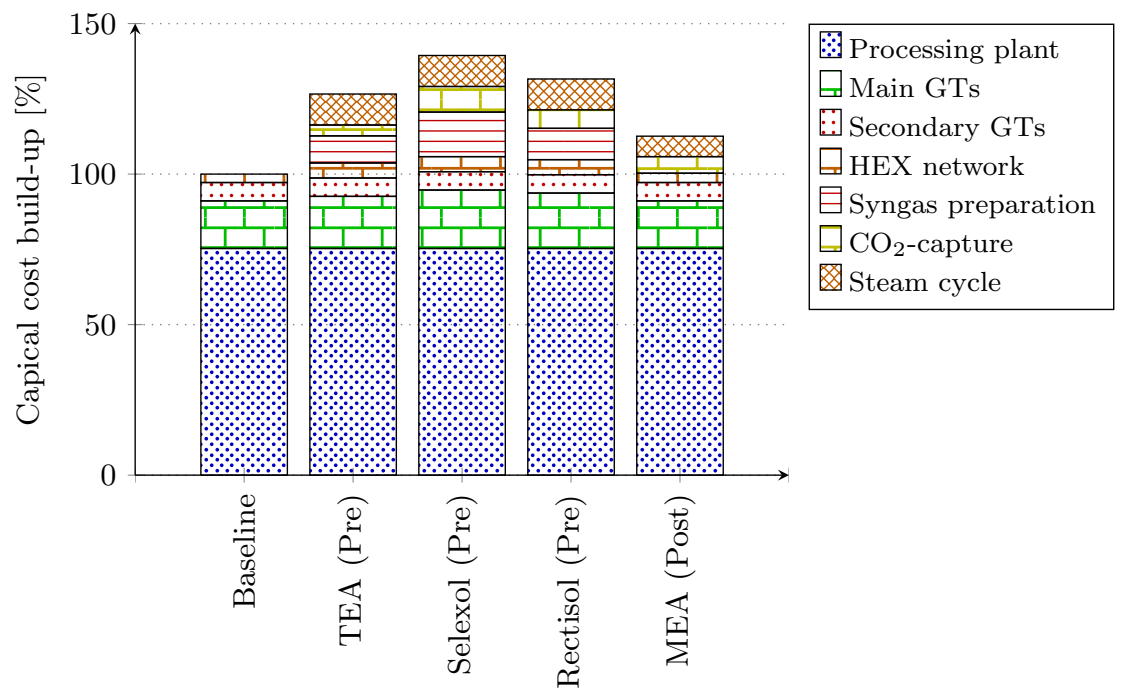

Figure 16: Capital cost build-up for offshore platforms with and without $\mathrm{CO}_{2}$-capture, based on the process equipments of the Draugen platform.

\subsubsection{Sensitivity analyses}

The economic profitability of $\mathrm{CO}_{2}$-mitigation options is impacted by several parameters and possible future policies in the offshore sector [42], and evaluating the sensitivity of the electricity and avoidance costs is thus of interest [43]. The ones that are considered the most important are the following:

- natural gas price;

- $\mathrm{CO}_{2}$ tax;

- capital costs of $\mathrm{CO}_{2}$-injection wells.

Their effects are assessed by performing sensitivity analyses on each of these three parameters, based on estimations found and deduced from studies available in the literature. Two post-combustion cases, derived from the multi-objective optimisation routine, are used as references for analysing the sensitivity of the electricity and $\mathrm{CO}_{2}$-avoidance costs for process configurations with medium- and high $\mathrm{CO}_{2}$-reduction potential.

The baseline values assumed for conducting the sensitivity analyses are a natural gas price of 8.08 \$/GJ, a lifetime of 30 years, site-specific costs of $\mathrm{M} \$ 15$, and a carbon tax of $65 \$ / \mathrm{t}_{\mathrm{CO}_{2}}$. The choice of these economic data is based on the current situation in Norway. Care should therefore be exercised when drawing conclusions about the economic profitability of $\mathrm{CO}_{2}$-mitigation options, as the conclusions drawn in the present study are based on a specific European case. The sensitivity of the COE and CAC is then investigated by keeping these parameters but one constant, and vary each single parameter individually, assuming it will not influence the value of the others. 
For readability, only the sensitivity analysis on the natural gas price is presented in the main matter, the other ones being shown in Appendix F.

Natural gas price. This evolution is difficult to predict, as it is highly different between European and American countries. In the past, the oil and gas prices have followed similar movements, but these trends have changed, at least in North America, because of geopolitical factors and the exploitation of shale gas. Changes in oil price were accounting for more than 40-65\% of the changes in gas price until 2009, but only for less than $25 \%$ since [44]. An increase of the gas prices, as described by most economic analyses, would push towards the implementation of waste heat recovery cycles because of the possible energy and gas savings. European gas prices are currently about twice as high as American ones, and they are projected to be around 10, 12 and $16 \$ / G J$ in 2020, 2030 and 2050, respectively [45]. The boundary values used for the sensitivity analysis on the natural gas price are derived from this resource, and validated with other works performed by the European Commission [42] and the International Energy Agency [46]. Further works [47] also suggest that this resource price will increase over years, as a result of the depletion of the natural gas resources.

The electricity and $\mathrm{CO}_{2}$-avoidance costs clearly follow a linear dependence on the natural gas price (Figure 17). At high natural gas prices, an oil and gas platform without $\mathrm{CO}_{2}$-capture appears to be the most competitive option if no carbon tax is set, but the implementation of waste heat recovery seems promising, as it results in fuel savings by up to $15 \%$ points. On the contrary, the interest for $\mathrm{CO}_{2}$-capture plants is small, since these processes reduce the energy efficiency of the power generation unit, resulting in greater natural gas consumption.

The introduction of a carbon tax, in this case of $65 \$ / \mathrm{t}_{\mathrm{CO}_{2}}$, increases the profitability of oil and gas platforms with $\mathrm{CO}_{2}$-capture. The first CCS process configuration appears to be competitive over a large range of natural gas prices, while the second one is only competitive for a resource price below $4 \$ /$ GJ. The same trends can be visualised by analysing the variations of the $\mathrm{CO}_{2}$-avoidance cost with the natural gas price, which increase more sharply in the second case.

\subsubsection{Economic scenarios}

There is a clear trade-off between the economic performance and the degree of $\mathrm{CO}_{2}$-abatement of oil and gas platforms, and the process configurations that are optimal will obviously differ depending on the field and the future economic scenarios (Table 1). The impacts of variations of parameters such as the natural gas price, $\mathrm{CO}_{2}$ tax, economic lifetime and capital costs are investigated by comparing three different scenarios, a low scenario, which corresponds to a situation where no $\mathrm{CO}_{2}$-tax is imposed on the offshore sector, a baseline scenario, which represents the current economic context in Norway, and a high scenario, which is characterised by a high $\mathrm{CO}_{2}$-tax. 

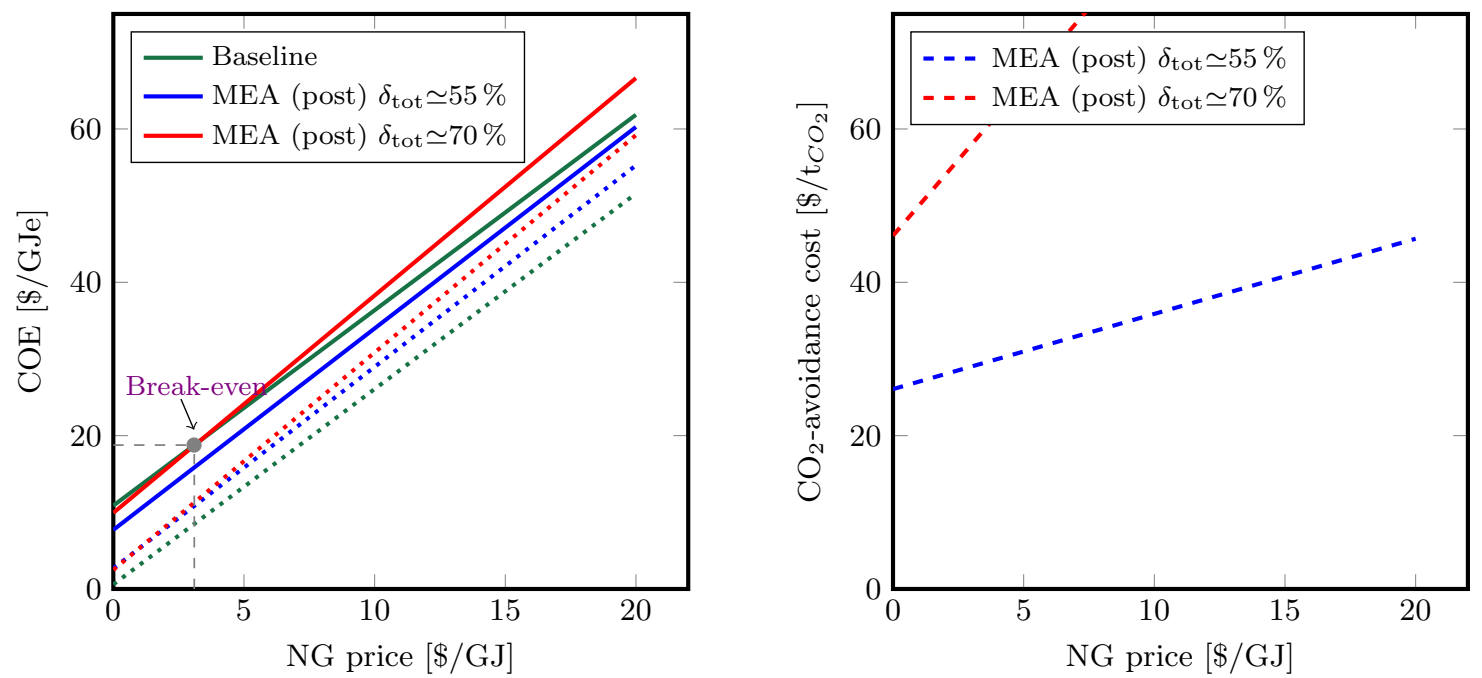

Figure 17: Sensitivity of the electricity production (COE) and avoidance (CAC) costs of an offshore platform with and without integration of post-combustion $\mathrm{CO}_{2}$-capture to the natural gas price, with (solid) and without (dotted) $\mathrm{CO}_{2}$-tax.

The low/high scenarios represent therefore extreme case scenarios, presenting the highest/lowest natural gas price and lowest/highest $\mathrm{CO}_{2}$-tax that may be expected in the future, based on the current estimates and trends. The baseline scenario presents strong similarities with the ones discussed in the works of the European Commission [42] and the International Energy Agency [46,47]. This approach of considering three values (low, middle and high) for the fuel costs was applied in other works, such as the techno-economic analysis conducted by the Zero Emission Platform [48]. The following results should not be viewed as precise technoeconomic results, but shall be seen as indications on the trends that can be expected, together with the results of the sensitivity analyses.

\begin{tabular}{llll} 
Table 1: Tested economic scenarios on the post-combustion & $\mathrm{CO}_{2}$-capture unit \\
\hline Scenario & Base & Low & High \\
\hline Natural gas price [\$/GJ] & 8.08 & 16.16 & 4.04 \\
$\mathrm{CO}_{2}$-tax $\left[\$ / \mathrm{tCO}_{2}\right]$ & 65.6 & 0.00 & 131.2 \\
Expected lifetime [years] & 30 & 20 & 40 \\
Capital costs $\left(\mathrm{CO}_{2}\right.$-wells $)[\mathrm{M} \$]$ & $\geq 15$ and $\leq 30$ & $\geq 30$ & $\leq 15$ \\
\hline
\end{tabular}

High $\mathrm{CO}_{2}$-capture rates are favoured with high $\mathrm{CO}_{2}$-tax, small well capital costs, and low gas costs, because the large economic penalties on the $\mathrm{CO}_{2}$-emissions compensate the additional investment costs of a $\mathrm{CO}_{2}$-capture unit and the possible benefits with a greater gas export. Medium $\mathrm{CO}_{2}$-capture rates, i.e. with a steam cycle only or with a small capture unit capacity, are preferable with high fuel gas production costs, since the integration of a waste heat recovery cycle allows for a smaller gas consumption on-site (Figure 18). 

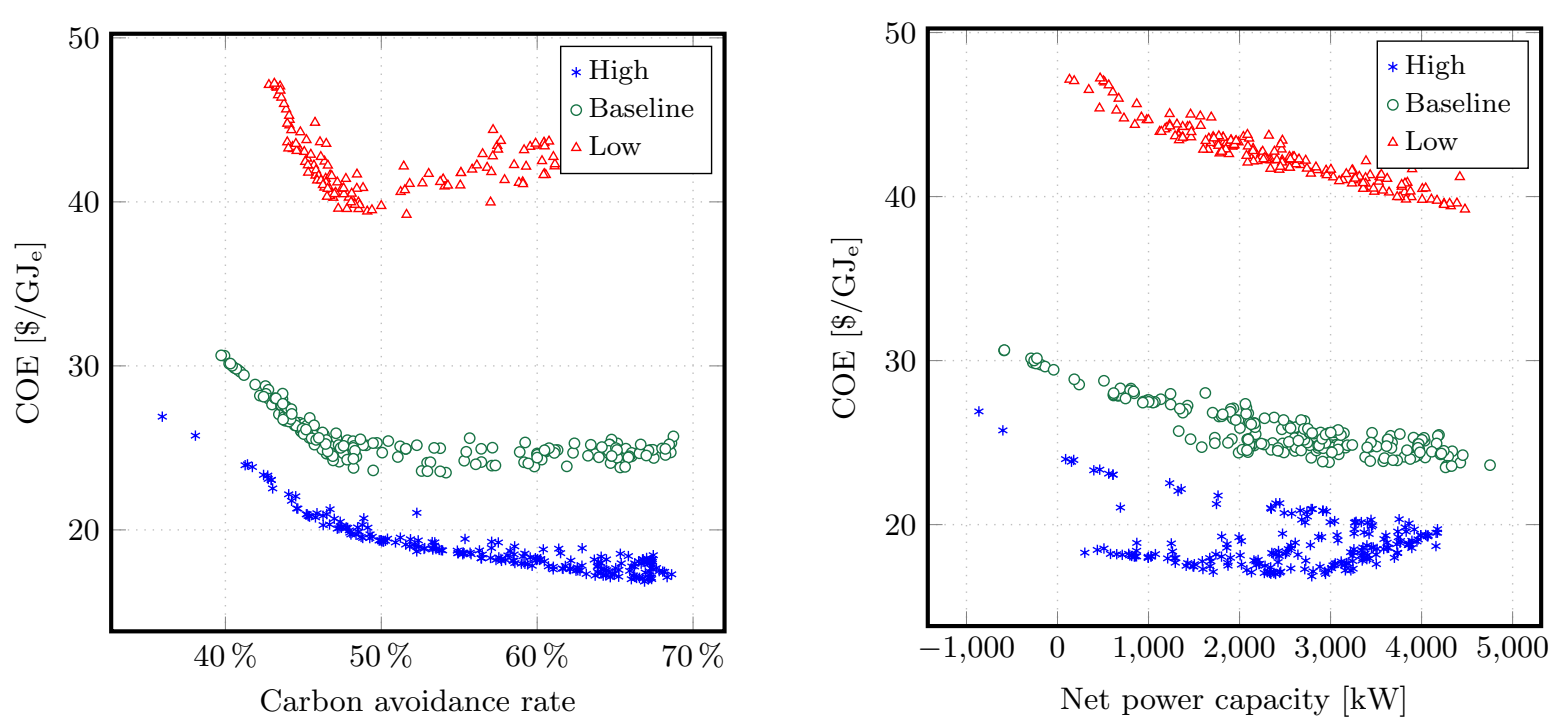

Figure 18: Pareto-optimal solutions for the site-scale integration of $\mathrm{CO}_{2}$-capture with steam networks: trade-off between the electricity cost (with $\mathrm{CO}_{2}$-tax), $\mathrm{CO}_{2}$-emissions and net power capacity.

\subsection{Environmental impact}

\subsubsection{Local and global emissions}

There is likewise a lack of knowledge on the environmental impact of $\mathrm{CO}_{2}$-capture plants on offshore platforms. The integration of such processes obviously results in a reduction of the local $\mathrm{CO}_{2}$-emissions, but the installation of additional equipment items and the discharge of amines to the environment may have other harmful impacts. In the case of electrification (Figure 19), the local fuel gas $\mathrm{CO}_{2}$-emissions are completely eliminated in Scenario 2 and decreased by about 90-95\% in Scenario 1. The remaining emissions consist of the release of methane, $\mathrm{CO}_{2}$ and other greenhouse gases by flaring and venting. The global emissions are reduced by up to $45 \%$ in Scenario 2 and by more than $50 \%$ in Scenario 1, if the supplied power comes from gas-fired combined cycle power plants with a thermal efficiency of $55 \%$. This bigger decrease in Scenario 1 can be explained by the lower transmission and conversion losses. There are, a priori, no $\mathrm{CO}_{2}$-emissions associated with fuel consumption if hydraulic power is used instead of natural gas.

\subsubsection{Life cycle assessment}

The environmental performance of the whole process chain, i.e. from the resource extraction to the decommissioning of the offshore platform, can be evaluated based on a life cycle assessment, considering several impacts (e.g. GWP) and various analyses methods (e.g. CML 2001 [49]). Only the results of the IPCC07 method are presented in the main matter, the results of the other assessments are given in Appendix G.

All configurations combining a steam network and a $\mathrm{CO}_{2}$-capture unit have, overall, a beneficial effect 


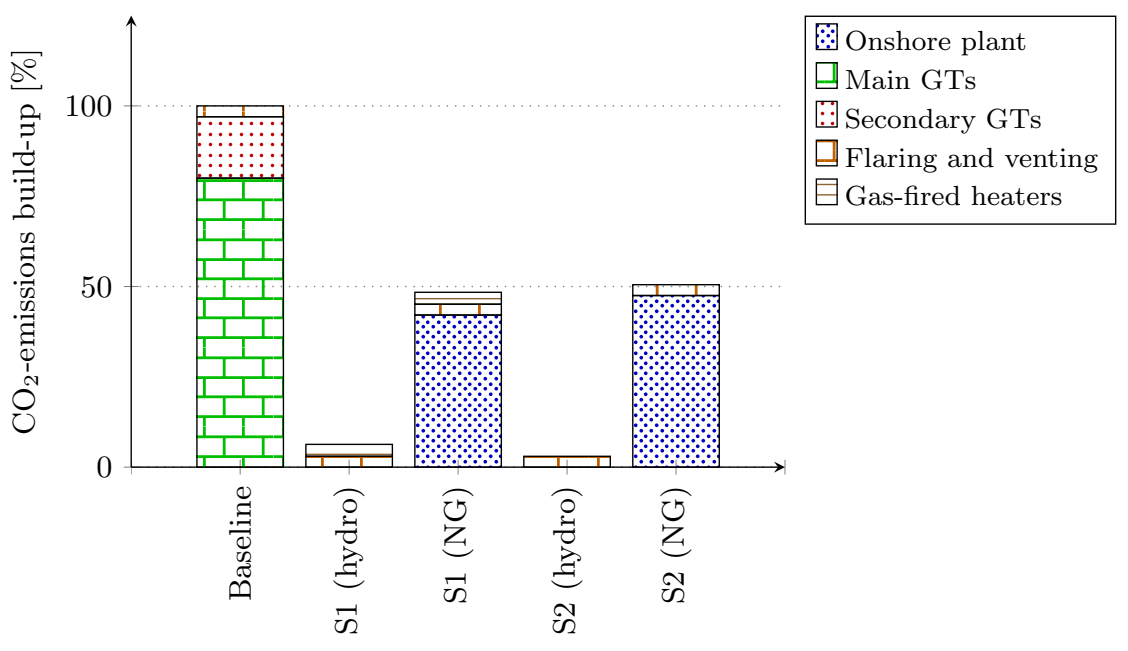

Figure 19: $\mathrm{CO}_{2}$-emissions build-up for offshore platforms with and without electrification.

with respect to the global warming potential impacts (Figure 20), because of the reductions in greenhouse gas emissions over the facility lifetime. The major contribution to the remaining GWP impact corresponds to the fossil $\mathrm{CO}_{2}$-emissions that are not sequestrated. The global warming potential effects associated with the construction and manufacturing of the process components are negligible in comparison.

Similarly, all configurations including electrification have a beneficial effect with regards the global warming potential impacts, because of the lower $\mathrm{CO}_{2}$-emissions over the lifetime of the offshore facility. The main contributions to the remaining impacts correspond to (i) the fuel emissions associated with the combustion of natural gas in power plants, (ii) the process components, including the voltage cables, and (iii) the flaring and venting discharges. The contributions from the voltage cables are much smaller than the contributions of the other process components, and are negligible compared to the emissions of the non-sequestrated $\mathrm{CO}_{2}$. However, these results build on the assumption that there is enough power on the electrical grid to meet the power demands offshore. The picture would likely be different if additional power plants have to be built as it would require additional resources and materials.

\section{Conclusion}

Different $\mathrm{CO}_{2}$-mitigation options for the offshore oil and gas sector were presented and compared, based on thermodynamic, economic and environmental performance indicators. The integration of processes such as steam bottoming cycles, pre- and post-combustion $\mathrm{CO}_{2}$-capture has been analysed, using a multi-disciplinary approach that combines thermodynamic analysis tools with optimisation routines and process integration methods.

In all cases, the integration of a steam network is revealed to be profitable, with an increase of the power generation capacity of up to $8 \mathrm{MW}$ and a greater gas export of up to $16 \%$. The integration of pre- and post- 


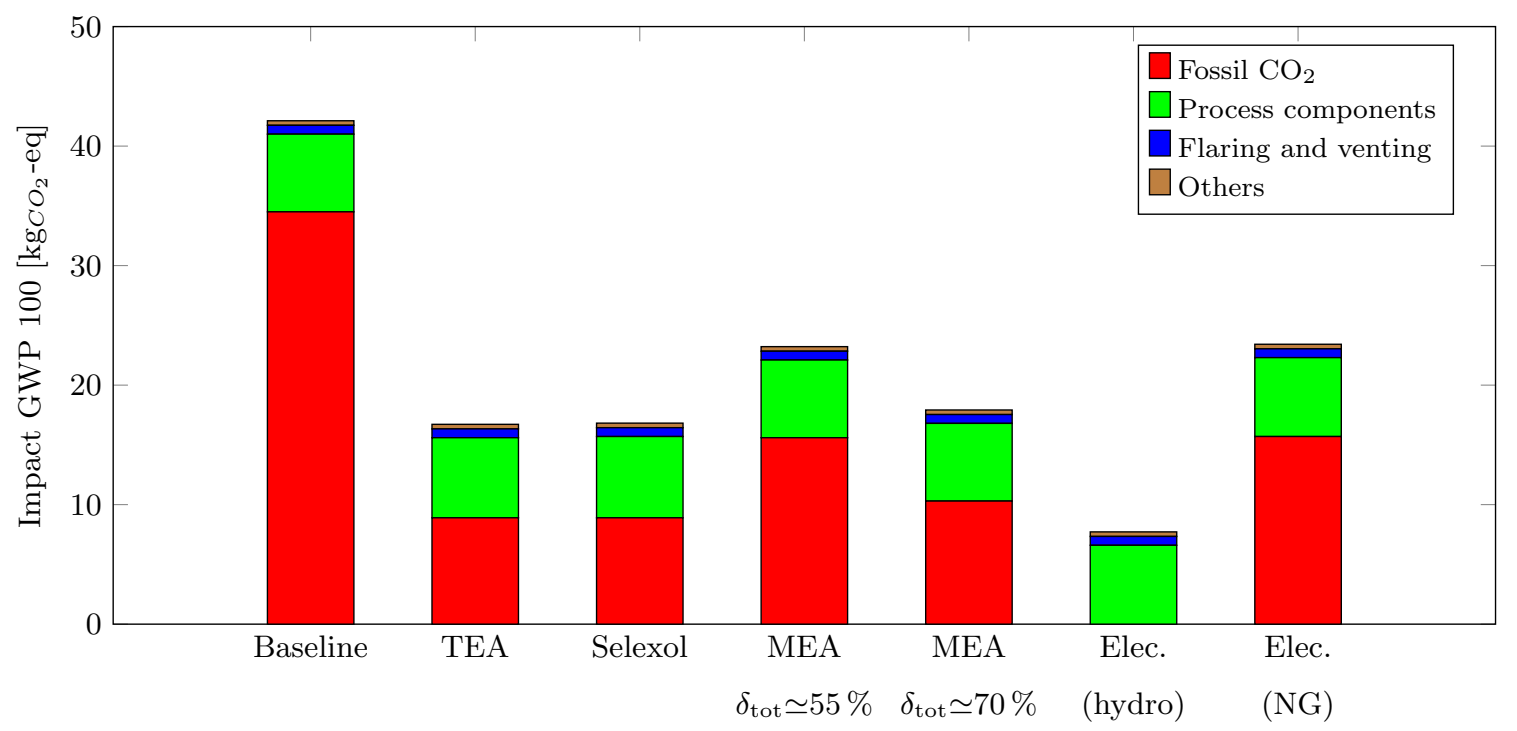

Figure 20: Comparison of the scenarios with and without $\mathrm{CO}_{2}$-capture: IPCC 07 (impact method) - GWP 100 (impact category)

combustion $\mathrm{CO}_{2}$-capture processes seems to be technically feasible, resulting in an energy penalty, but in lower $\mathrm{CO}_{2}$-emissions and therefore greater operating profits. The multi-objective optimisations help assess the trade-off between the gain in power production, reduction in $\mathrm{CO}_{2}$-emissions, and additional investment costs. The sensitivity analyses demonstrate that the economic context, i.e. the value of the $\mathrm{CO}_{2}$-tax, the economic field lifetime, and the natural gas market price, has a critical importance on the profitability of all these options.

Electrifying an oil and gas platform is shown to be beneficial both from a thermodynamic and environmental prospective, because onshore power plants have a higher efficiency than the gas turbines installed on offshore platforms. The reductions in $\mathrm{CO}_{2}$-emissions strongly depend on whether the electricity available on the grid is generated from gas-fired combined cycle power plants or hydroelectric facilities.

Finally, it can be concluded that the combination of process integration tools and life cycle assessments illustrates the benefits of mitigating $\mathrm{CO}_{2}$-emissions in the offshore oil and gas sector. Each option may be promising or competitive in the future, if economic incentives are taken to push the offshore industries towards the development of more energy-efficient and environmental-friendly solutions.

\section{Acknowledgments}

The funding from the Norwegian Research Council through the Petromaks programme, within the project 2034/E30 led by Teknova is acknowledged. 


\section{References}

[1] Norwegian Ministry of Petroleum and Energy, . Facts 2012 - The Norwegian Petroleum Sector. Tech. Rep.; Norwegian Petroleum Directorate; Oslo, Norway; 2012.

[2] Norway to set high carbon tax on oil and gas production. 2012.

[3] de Oliveira Jr., S., Van Hombeeck, M.. Exergy Analysis of Petroleum Separation Processes in Offshore Platforms. Energy Conversion and Management 1997;38(15-17):1577-1584.

[4] Voldsund, M., Ertesvåg, I., He, W., Kjelstrup, S.. Exergy Analysis of the Oil and Gas Processing a Real Production Day on a North Sea Oil Platform. Energy 2013;55:716-727.

[5] Nguyen, T.V., Jacyno, T., Breuhaus, P., Voldsund, M., Elmegaard, B.. Thermodynamic analysis of an upstream petroleum plant operated on a mature field. Energy 2014;68:454-469.

[6] Voldsund, M., Nguyen, T.V., Elmegaard, B., Ertesvåg, I., Røsjorde, A., Jøssang, K., et al. Exergy destruction and losses on four North Sea offshore platforms: A comparative study of the oil and gas processing plants. Energy $2014 ; 74: 45-58$.

[7] Nguyen, T.V., Fülöp, T., Breuhaus, P., Elmegaard, B.. Life performance of oil and gas offshore platforms -site-scale integration and exergy-based assessment. Energy 2014;73:282-301.

[8] Kloster, P.. Energy Optimization on Offshore Installations with Emphasis on Offshore and Combined Cycle Plants. In: Proceedings of the Offshore Europe Conference. Aberdeen, UK: Society of Petroleum Engineers; 1999, p. 1-9 (Paper SPE $56964)$.

[9] Kloster, P.. Reduction of Emissions to Air Through Energy Optimisation on Offshore Installations. In: Proceedings of the SPE International Conference on Health, Safety, and the Environment in Oil and Gas Exploration and Production. Stavanger, Norway: Society of Petroleum Engineers; 2000, p. 1-7 (Paper SPE 61651).

[10] Nord, L., Bolland, O.. Design and off-design simulations of combined cycles for offshore oil and gas installations. Applied Thermal Engineering 2013;54:85-91.

[11] Pierobon, L., Nguyen, T.V., Larsen, U., Haglind, F., Elmegaard, B.. Multi-objective optimization of organic rankine cycles for waste heat recovery: Application in an offshore platform. Energy 2013;58:538 - 549.

[12] Barrera, J., Bazzo, E., Kami, E.. Exergy analysis and energy improvement of a Brazilian floating oil platform using Organic Rankine Cycles. Energy 2015;88:67-79. doi:10.1016/j.energy .2015.03.091.

[13] Nguyen, T.V., Tock, L., Maréchal, F., Elmegaard, B.. Oil and gas platforms with steam bottoming cycles: Retrofit integration and thermo-environomic evaluation. Applied Energy 2014;131:222-237.

[14] Sánchez, Y., de Oliveira Jr., S.. Exergy analysis of petroleum offshore platform process plant with $\mathrm{CO}_{2}$ capture. Energy $2015 ; 88: 46-56$.

[15] Econ Pöyri, . CO $\mathrm{CO}_{2}$-emissions effect of electrification. Tech. Rep. R-2011-041; Statoil ASA; Oslo, Norway; 2011.

[16] He, W., Uhlen, K., Hadiya, M., Chen, Z., Shi, G., del Rio, E.. Case study of Integrating an Offshore Wind Farm with Offshore Oil and Gas Platforms and with an Onshore Electrical Grid. Journal of Renewable Energy 2013;2013(ID 607165):1-11.

[17] Bolliger, R., Becker, H., Maréchal, F.. New generic approach for the analysis of energy conversion system models. Computer Aided Chemical Engineering 2009;27:243-248.

[18] Turton, R., Bailie, R., Whiting, W., Shaeiwitz, J., Bhattacharyya, D.. Analysis, Synthesis and Design of Chemical Processes. Prentice Hall International Series in the Physical and Chemical Engineering Sciences; 4th ed.; Upper Saddle River, United States: Prentice Hall; 2012.

[19] Molyneaux, A.. A practical evolutionary method for the multi-objective optimisation of complex integrated energy systems including vehicle drivetrains. Ph.D. thesis; École Polytechnique Fédérale de Lausanne; Lausanne, Switzerland; 2002. 
[20] Aspen Technology, . Aspen Plus - Modelling Petroleum Processes. Burlington, USA; 1999.

[21] Linnhoff, B.. Pinch analysis - a state-of-the-art overview. Chemical Engineering Research and Design 1993;71(A5):503522 .

[22] Smith, R.. Chemical Process: Design and Integration; vol. 50. John Wiley \& Sons; 2005.

[23] Kotas, T.. The Exergy Method of Thermal Plant Analysis. London, United Kingdom: Krieger Publishing; 1995.

[24] Linnhoff, B.. Pinch technology for the synthesis of optimal heat and power systems. Journal of Energy Resources Technology, Transactions of the ASME 1989;111(3):137-147.

[25] Gerber, L., Gassner, M., Maréchal, F.. Systematic integration of lca in process systems design: Application to combined fuel and electricity production from lignocellulosic biomass. Computers and Chemical Engineering 2011;35(7):1265-1280.

[26] Swiss Centre for Life Cycle Inventories, . Ecoinvent. Tech. Rep.; Empa; Duebendorf, Switzerland; 2013.

[27] Maréchal, F., Kalitventzeff, B.. Targeting the optimal integration of steam networks: Mathematical tools and methodology. Computers and Chemical Engineering 1999;23(SUPPL. 1):S133-S136.

[28] Nord, L., Bolland, O.. Steam bottoming cycles offshore - challenges and possibilities. Journal of Power Technologies $2013 ; 92(3): 201-207$.

[29] Burr, B., Lyddon, L.. A comparison of physical solvents for acid gas removal. In: Proceedings of the 87th Annual Gas Processors Association Convention. Grapevine, United States; 2008, p. 1-13.

[30] Tock, L., Maréchal, F.. $\mathrm{H}_{2}$ processes with $\mathrm{CO}_{2}$ mitigation: Thermo-economic modeling and process integration. International Journal of Hydrogen Energy 2012;37(16):11785-11795.

[31] Kanniche, M., Gros-Bonnivard, R., Jaud, P., Valle-Marcos, J., Amann, J.M., Bouallou, C.. Pre-combustion, postcombustion and oxy-combustion in thermal power plant for $\mathrm{CO}_{2}$ capture. Applied Thermal Engineering 2010;30(1):53-62.

[32] Consonni, S., Vigano, F.. Decarbonized hydrogen and electricity from natural gas. International Journal of Hydrogen Energy 2005;30(7):701-718.

[33] Tarun, C., Croiset, E., Douglas, P., Gupta, M., Chowdhury, M.. Techno-economic study of $\mathrm{CO}_{2}$ capture from natural gas based hydrogen plants. International Journal of Greenhouse Gas Control 2007;1(1):55-61.

[34] Tock, L.. Thermo-environomic optimisation of fuel decarbonisation alternative processes for hydrogen and power production. Ph.D. thesis; École Polytechnique Fédérale de Lausanne; Lausanne, Switzerland; 2013.

[35] Chiesa, P., Lozza, G., Mazzocchi, L.. Using hydrogen as gas turbine fuel. In: ASME Turbo Expo 2003, collocated with the 2003 International Joint Power Generation Conference. American Society of Mechanical Engineers; 2003 , p. $163-171$.

[36] McDonell, V.. Key combustion issues associated with syngas and high-hydrogen fuels. Tech. Rep.; National Energy Technology Laboratory; Irvine, United States; 2006.

[37] Pierobon, L., Kandepu, R., Haglind, F.. Waste Heat Recovery for Offshore Applications. In: Proceedings of the ASME 2012 International Mechanical Engineering Congress and Exposition; vol. 6: Energy, Parts A and B. ASME; 2012, p. $503-512$.

[38] Chen, C.C., Song, Y.. Generalized Electrolyte-NRTL Model for Mixed-Solvent Electrolyte Systems. AIChE Journal 2004;50(8):1928-1941.

[39] Redlich, O., Kwong, J.. ON THE THERMODYNAMICS OF SOLUTIONS. V An Equation of State. Fugacities of Gaseous Solutions. Chemical Reviews 1949;44:233-244.

[40] Gross, J., Sadowski, G.. Perturbed-Chain SAFT: An Equation of State Based on a Perturbation Theory for Chain Molecules. Industrial \& Engineering Chemistry Research 2001;40(4):1244-1260.

[41] Statoil,. Annual report 2010 - average production cost and sales prices. 2010.

[42] Directorate-General for Energy, . EU energy trends to 2030 - Update 2009. Commission staff working paper; European Commission; Brussels, Belgium; 2009.

[43] Abu-Zahra, M.R., Niederer, J.P., Feron, P.H., Versteeg, G.F.. CO CO $_{2}$ capture from power plants: Part II. A paramet- 
ric study of the economical performance based on mono-ethanolamine. International journal of greenhouse gas control $2007 ; 1(2): 135-142$.

[44] Energy \& Financial Markets - What drives crude oil prices? 2015.

[45] European Climate Foundation (ECF), . Energy Roadmap 2050 Impact Assessment Part 2 including Part II of Annex 1 'Scenarios - assumptions and results' and Annex 2 'Report on Stakeholders scenarios'. Commission staff working paper SEC(2011)1565/2; European Commission; Brussels, Belgium; 2011.

[46] International Energy Agency, . Medium-term Oil \& Gas Markets. Tech. Rep.; OECD/IEA; Paris, France; 2011.

[47] International Energy Agency, . Key World Energy Statistics. Tech. Rep.; OECD/IEA; Paris, France; 2012.

[48] European Technology Platform for Zero Emission Fossil Fuel Power Plants, . The Costs of CO 2 Capture - Postdemonstration CCS in the EU. Tech. Rep.; Zero emissions platform (ZEP); Brussels, Belgium; 2011.

[49] Guinée, J., Gorrée, M., Heijungs, R., Huppes, G., Kleijn, R., de Koning, A., et al. Handbook on life cycle assessment. Operational guide to the ISO standards. I: LCA in perspective. IIa: Guide. IIb: Operational annex. III: Scientific background. Dordrecht, The Netherlands: Kluwer Academic Publishers; 2002.

[50] Maréchal, F., Kalitventzeff, B.. Process integration: Selection of the optimal utility system. Computers and Chemical Engineering 1998;22(SUPPL.1):S149-S156.

[51] Ulrich, G.. A guide to chemical engineering process design and economics. Chichester, United Kingdom: Wiley; 1984.

[52] Vik, E., Dinning, A.. Produced Water Re-Injection - The Potential to Become an Improved Oil Recovery Method. Tech. Rep.; Aquatem A/S; Oslo, Norway; 2009.

[53] European Commission, . The state of the European carbon market in 2012. Report from the commission to the European Parliament and the council SEC(2011)1565/2; European Parliament; Brussels, Belgium; 2011.

[54] Goedkoop, M., Spriensma, R.. The eco-indicator99: A damage oriented method for life cycle impact assessment: Methodology report. Tech. Rep. 1999/36A; Ministerie van Volkshuisvesting, Ruimtelijke Ordening en Milieu; Amersfoort, The Netherlands; 2001.

\section{Appendix A. Thermodynamic relations}

In the case of an offshore platform, energy enters and exits this system with material streams (e.g. petroleum feed, imported gas, fuel air, as well as oil, gas and produced water), with power (e.g. imported or exported electricity from the mainland or to other platforms) and with heat (e.g. heat losses by component radiation). Without considering the special cases with imported gas (e.g lift purposes) or power import (e.g. electrification), the energy balance for the processing and utility plants of the oil and gas facility can then be expressed as:

$$
\begin{aligned}
& \dot{H}_{\text {feed }}+\dot{W}_{\mathrm{UT}}+\dot{Q}_{\mathrm{UT}, \text { heat }}=\sum_{k} \dot{H}_{k}+\dot{Q}_{\mathrm{PP}, \text { cool }} \\
& \dot{H}_{\mathrm{k}, \text { fuel }}+\dot{H}_{\text {air }}=\dot{Q}_{\mathrm{UT}, \text { cool }}+\dot{Q}_{\mathrm{UT}, \text { heat }}+\dot{W}_{\mathrm{UT}}
\end{aligned}
$$

where:

- $\dot{H}$ stands for the energy rate carried with the ingoing material flows (feed denoting the feed streams from the wells); 
- or for the outgoing streams;

- $\dot{W}$ for the energy transported with power, imported or exported to the mainland or other platforms.

- $\dot{W}_{\mathrm{UT}}$ is the power consumed within the separation and treatment modules, as well as in electric heaters, which is produced in the utility plant;

- $\dot{Q}_{\mathrm{PP}, \text { heat }}$ is the heat entering the processing plant, generally by direct heat exchange with the exhausts of a gas turbine, or by indirect heat exchange, by using a heating medium (e.g. hot water or hot glycol);

- $\dot{Q}_{\mathrm{PP}, \text { cool }}$ is the heat entering the processing plant, generally by direct heat exchange with the exhausts of a gas turbine, or by indirect heat exchange, by using a heating medium (e.g. hot water or hot glycol);

- $\dot{Q}_{\mathrm{UT}, \text { cool }}$ is the energy transferred from the power plant to the cooling medium (e.g. cooling air, seawater or glycol-water mixtures) in, for instance, a steam condenser.

In details, the exergy balances can thus be expressed as:

$$
\begin{aligned}
& \dot{E}_{\text {feed }}+\dot{E}_{\mathrm{imp}}+\dot{E}_{\mathrm{air}}+\dot{E}_{\mathrm{cw}}+\dot{E}_{\mathrm{imp}}^{W}=\sum_{k} \dot{E}_{k}+\dot{E}_{\mathrm{exh}}+\dot{E}_{\mathrm{rw}}+\dot{E}_{\mathrm{exp}}^{W}+\dot{E}_{\mathrm{d}, \mathrm{OP}} \\
& \dot{E}_{\mathrm{feed}}+\dot{E}_{\mathrm{UT}}^{W}+\dot{E}_{\mathrm{UT}, \text { heat }}^{Q}=\sum_{k} \dot{E}_{k}+\dot{E}_{\mathrm{PP}, \mathrm{cool}}^{Q}+\dot{E}_{\mathrm{d}, \mathrm{PP}} \\
& \dot{E}_{\mathrm{k}, \text { fuel }}+\dot{E}_{\mathrm{air}}=\dot{E}_{\mathrm{UT}, \mathrm{cool}}^{Q}+\dot{E}_{\mathrm{UT}, \text { heat }}^{Q}+\dot{E}_{\mathrm{UT}}^{W}+\dot{E}_{\mathrm{exh}}
\end{aligned}
$$

where:

- $\dot{E}$ denotes the exergy flow associated with a given stream of matter;

- $\dot{E}^{W}$ denotes the exergy transferred with power, and has the same value than its energy;

- $\dot{E}^{Q}$ denotes the exergy transferred with heat, and has a smaller value than its energy, as it depends on the temperatures of the environment and at which the heat transfer takes place;

- $\dot{E}_{\mathrm{d}}$ is the exergy destroyed in the overall (OP), processing (PP) and utility plants (UP);

- imp denotes the imported gas for injection or power generation, air for the air processed through the gas turbines, cw stands for the seawater used for cooling needs, exh for the exhaust gases, rw for the treated and rejected cooling water, and $\mathrm{k}$ for the several oil and gas streams. 


\section{Appendix B. Energy integration}

The heat cascade problem is formulated as a MILP (Mixed Integer Linear Programming) problem, assessing precisely the heating and cooling requirements of the system under study. It follows the work of Maréchal et al. [50], with the aim of minimising the operating costs associated with the selection and use of the utilities (e.g. process water and seawater). The heating demand is satisfied by waste heat recovery from the turbine exhausts, while the cooling demand is met by processing seawater or recovering cooling water from the processing plant.

At first, the stream temperatures are corrected $\left(\mathrm{T}^{*}\right)$ considering individual temperature differences $\left(\Delta \mathrm{T}_{\min } / 2\right)$ of $2 \mathrm{~K}, 4 \mathrm{~K}$ and $8 \mathrm{~K}$ for phase-changing, liquid and gas streams.

$$
\begin{aligned}
T_{\text {hot }}^{*} & =\left(T_{\text {hot }}-\frac{\Delta T_{\text {min }}}{2}\right) \\
T_{\text {cold }}^{*} & =\left(T_{\text {cold }}+\frac{\Delta T_{\text {min }}}{2}\right)
\end{aligned}
$$

The resulting mass and energy balances are established for the process subsections based on the process models. The aim is to evaluate how their energy requirements can be satisfied, by promoting internal heat recovery and minimising the operating costs associated with the external utilities. The objective function of this optimisation problem can be written as:

$$
\min \sum_{s=1}^{N_{s}} f_{s} \cdot \dot{C}_{\mathrm{O}, s}+c_{e^{+}} \dot{W}_{\mathrm{g}}^{+}-c_{e^{-}} \dot{W}_{\mathrm{g}}^{-}
$$

with:

$N_{s}$, the number of subsystems, processes and utilities $s$

$f_{s}$, the level of utilisation of the process or sub-system $s$;

$\dot{C}_{\mathrm{O}, s}$, the operating costs associated with the sub-system $s$;

$c_{e^{+}}$and $c_{e^{-}}$, the purchase and sales prices for electricity;

$\dot{W}_{\mathrm{g}}^{+}$and $\dot{W}_{\mathrm{g}}^{-}$, the imported and exported electricity from and to the grid.

The multiplication factor $f_{s}$ represents the usage rate of the sub-system $s$. It is equal to 1 if the subsystem of interest is a process unit, i.e. a unit with a determined flow-rate and energy demand, and is variable in a certain range if it is a utility unit, i.e. a unit with variable flow-rate (e.g. seawater, with a flow rate that can be varied by the operator to match the system cooling demand).

Each utility unit is therefore defined by a minimum $\left(f_{\min , s}\right)$ and maximum usage rate $\left(f_{\max , s}\right)$, which correspond to the lower and upper usage bounds. For example, for seawater, the maximum usage rate on 
an offshore platform is determined by the maximum amount of water that can be processed in the seawater lift pumps. Moreover, when comparing and selecting different utilities, such as air and seawater for cooling purposes, an optimal solution may be to use only seawater, and an integer variable $y_{s}$ is added in the MILP problem to account for these on/off aspects. In this example, the activation variable would be equal to 1 for seawater and 0 for air.

$$
\forall s \in\left[1, n_{s}\right], y_{s} \in\{0,1\}, f_{\min , s} y_{s} \leq f_{s} \leq f_{\max , s} y_{s}
$$

This objective function is subject to process and thermodynamic limitations, such as the mass and energy balances, as well as the heat cascade constraints:

- heat balance for each temperature interval $k$ :

$$
\forall k \in\left[1, N_{k}\right], \sum_{s=1}^{N_{s}} f_{s} \cdot\left(\sum_{h_{k}=1}^{N_{s_{h, k}}} \dot{Q}_{N_{s_{h, k}}}-\sum_{c_{k}=1}^{N_{s_{c, k}}} \dot{Q}_{n_{s_{c, k}}}\right)+\dot{R}_{k+1}-\dot{R}_{k}=0
$$

- overall heat balance:

$$
\dot{R}_{1}=0, \dot{R}_{N_{k+1}}=0, \forall k \in\left[2, N_{k}\right] \dot{R}_{k} \geq 0
$$

- electricity consumption:

$$
\sum_{s=1}^{N_{s}} f_{s} \dot{W}_{s}^{-}-\dot{W}_{\mathrm{aux}}^{+}+\varepsilon_{\mathrm{g}, s} \dot{W}_{\mathrm{g}}^{+} \leq 0
$$

- electricity export:

$$
\sum_{s=1}^{N_{s}} f_{s} \dot{W}_{s}^{-}-\dot{W}_{\mathrm{aux}}^{+}+\varepsilon_{\mathrm{g}, s} \dot{W}_{\mathrm{g}}^{+}-\frac{\dot{W}_{\mathrm{g}}^{+}}{\varepsilon_{s, \mathrm{~g}}}=0
$$

- overall electricity balance:

$$
\dot{W}^{+} \leq 0, \dot{W}^{-} \leq 0
$$

with:

$N_{k}$, the number of temperature intervals $k$;

$\dot{W}_{s}^{-}$, the net power production of the sub-system $s$ in reference conditions;

$\dot{W}_{\text {aux }}^{+}$, the auxiliary power consumption on-site, not assigned to any sub-system $s$;

$\varepsilon_{\mathrm{g}, s}$ and $\varepsilon_{s, \mathrm{~g}}$ the conversion efficiency from the grid to the sub-system $s$, and from the sub-system $s$ to the grid;

$\dot{Q}_{N_{s_{h, k}}}$ and $\dot{Q}_{N_{s_{c, k}}}$, the thermal loads associated with the hot stream $h$ and cold stream $c$ in the temperature interval $k$ and sub-system $s$; 
$\dot{R}_{k}$, the residual heat load from the temperature interval $k$, cascaded to the lower one $k+1$.

These constraints ensure that the problem is sound from a thermodynamic point of view, and that the utilities that are the most interesting from an economic perspective are selected.

\section{Appendix C. Economic evaluation}

The retrieval of the mass and energy balances from the process and energy integration models can then be used for performing preliminary cost estimations, following the method of Turton et al. [18]. The grassroot costs $C_{\mathrm{gr}}$ represent the total investment costs, deduced from the bare module costs $C_{\mathrm{bm}}$ and purchased equipment costs $C_{\mathrm{pc}}$. The total grassroot costs are calculated following these four steps:

1. the purchased-equipment costs of each item $C_{\mathrm{pc}}$ are estimated by cost correlations, such as the ones of Turton et al.[18], which have an uncertainty of $\pm 30 \%$, or by estimation charts, assuming atmospheric pressure conditions and carbon steel construction:

$$
\log _{10} C_{\mathrm{pc}}=k_{1}+k_{2} \log _{10} A+k_{3}\left(\log _{10} A\right)^{2}
$$

where $k_{1}, k_{2}$ and $k_{3}$ are constants and $A$ is the capacity or size parameter specific to the component under study (e.g. heat transfer area for heat exchangers).

2. the bare module costs $C_{\mathrm{bm}}^{0}$ are obtained, adjusting the purchased-equipment costs with pressure $\left(f_{p}\right)$ and material $\left(f_{m}\right)$ factors:

$$
C_{\mathrm{bm}}^{0}=C_{\mathrm{pc}}\left(b_{1}+b_{2} f_{m} f_{p}\right)
$$

where $b_{1}$ and $b_{2}$ are constants. In some cases, these correlations should be adapted to include designtype and temperature factors to correct these base costs.

3. the actualised bare module $\operatorname{costs} C_{\mathrm{bm}}$ are computed, considering the inflation between the reference year of the cost data and the date of the estimate with the Marshall Swift Indexes:

$$
C_{\mathrm{bm}}=C_{\mathrm{bm}}^{0}\left(\frac{\mathrm{MSI}}{\mathrm{MSI}^{0}}\right)
$$

4. the grassroot $\operatorname{costs} C_{\mathrm{gr}}$, i.e. the total investment costs when installing the equipment items on a new production site, are deduced from:

$$
C_{\mathrm{gr}}=\left(1+\alpha_{1}\right) \sum_{i} C_{\mathrm{bm}, i}+\alpha_{2} \sum_{i} C_{\mathrm{bm}, i}^{0}
$$

where the factor $\alpha_{1}(\simeq 0.18)$, which depends on the process conditions, accounts for the contingencies $(\simeq 0.15)$ and fees $(\simeq 0.03)$, and the factor $\alpha_{2}(\simeq 0.35)$, which is independent of the process operation, accounts for the auxiliary facilities and site development. 
The capacity factor and values of the coefficients $k$ used in this work to calculate the purchased equipment costs for the most important equipments are the following:

- for centrifugal pumps with electric drives, the capacity factor is the shaft power in $\mathrm{kW}$, and $k_{1}, k_{2}$ and $k_{3}$ are $3.5793,0.3208$ and 0.02850 ;

- for centrifugal compressors, the capacity factor is the fluid power in $\mathrm{kW}$, and $k_{1}, k_{2}$ and $k_{3}$ are 2.9945 , 0.9542 and 0 ;

- for axial gas turbines, the capacity factor is the shaft power in $\mathrm{kW}$, and $k_{1}, k_{2}$ and $k_{3}$ are 3.5137 , 0.5888 and 0

- for vertical vessels such as scrubbers, the capacity factor is the height in $\mathrm{m}$, and $k_{1}, k_{2}$ and $k_{3}$ are $3.6237,0.5262$ and 0.2146 ;

- for horizontal vessels such as 2- and 3-phase separators, the capacity factor is the length in $\mathrm{m}$, and $k_{1}$, $k_{2}$ and $k_{3}$ are $3.3592,0.5905$ and 0.1106 .

The vessel costs are directly related to their dimensions, which are themselves deduced from the volume flowrate of the feed flow. A maximum diameter of $3 \mathrm{~m}$, height of $4 \mathrm{~m}$ and height to diameter ratio of $4 / 1$ is considered for vertical vessels.

The column costs are calculated with the correlations presented in Ulrich et al. [51]

\section{Appendix D. Platform information}

The offshore platform investigated in this work (Figure D.21) has been in production for more than 20 years and processes oil, gas and water. The initial hydrostatic pressure and reservoir temperature were about 165 bar and $71{ }^{\circ} \mathrm{C}$ [52]. Petroleum and subsurface water enter the platform system through the production manifolds, in which the streams from the several wells are depressurised and mixed. The pressures at the inlet of the production manifold range between 8 and 46 bar, and the average temperatures are about 63 ${ }^{\circ} \mathrm{C}$.

Oil, gas and water are then dissociated by gravity in two separation stages, the first ones operating at the production manifold conditions, the second one at about $65-75{ }^{\circ} \mathrm{C}$ and $1.6-1.8$ bar. The recovered gas is first re-compressed to the initial feed pressure, and compressed further to 179-189 bar. Most high-pressure dry gas leaving the final compression stage is used for gas lift. The remaining gas is partly exported to the coast and partly consumed in gas turbines for local power generation. The crude oil is stored and exported to the shore, while the produced water is treated and discharged into the sea. The gas turbines amount to five, of which three provide the power required in the processing plant, and the remaining two are run in case of water injection. Additional process data is provided in Nguyen et al. [5]. 


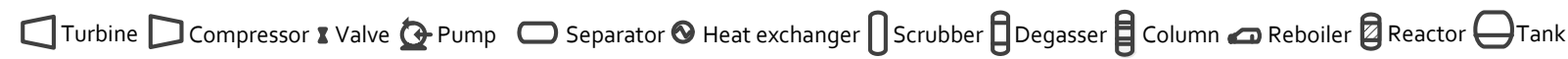

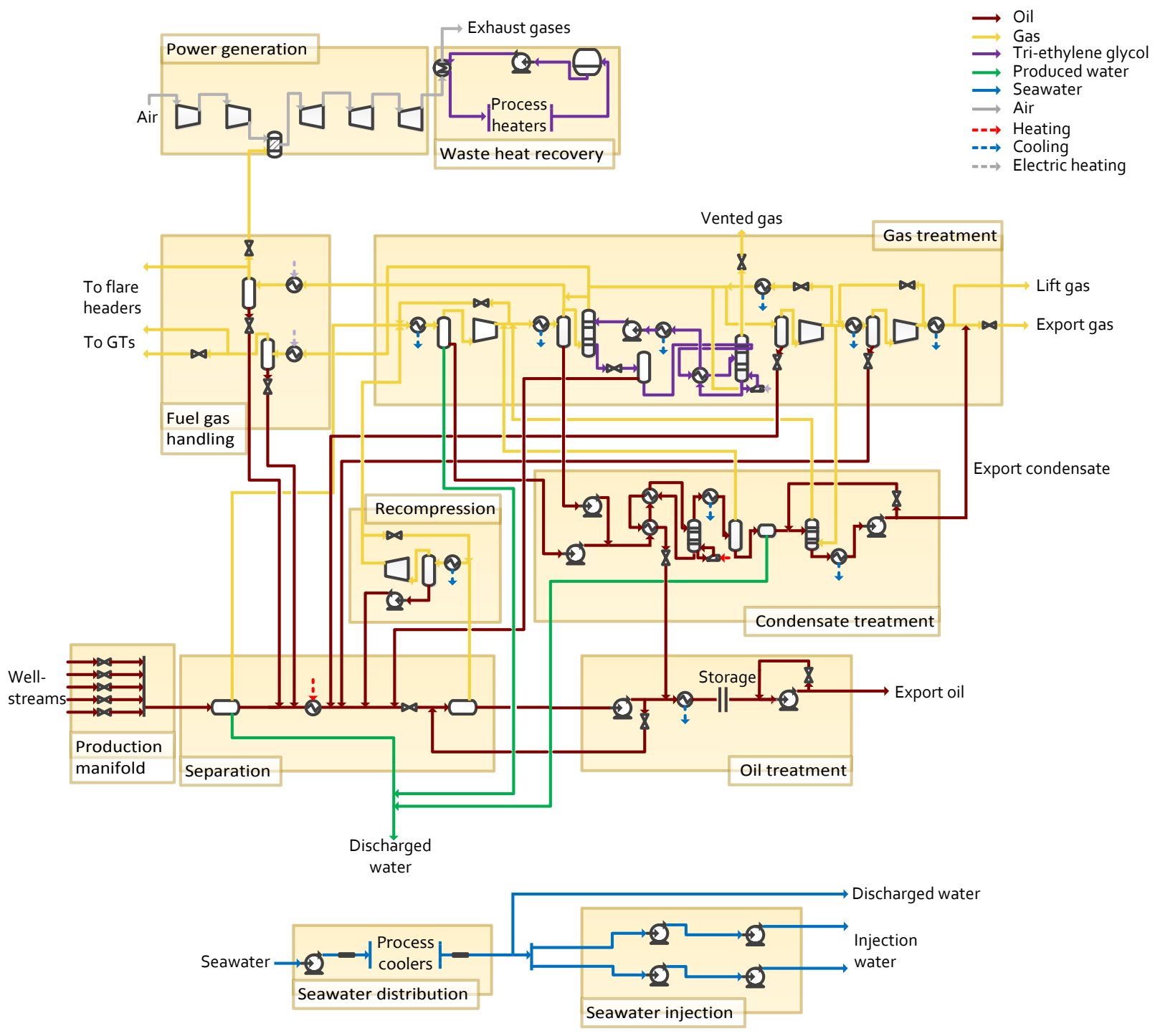

Figure D.21: Process flow diagram of the Norwegian Sea offshore platform investigated in this work, based on input by Norske Shell A/S and data collected from the literature. For ease of reading, only the most significant recycling loops are drawn, and only one gas turbine is shown. The addition of chemicals such as glycol and methanol to prevent hydrate formation is not indicated, and redundant components that are run in parallel (e.g. pumps and separators) are merged into one. 


\section{Appendix E. Multi-objective optimisation}

The decision variables of the multi-objective optimisation problem are presented, in the case of the $\mathrm{CO}_{2}$ capture processes, as follows. They correspond to the selection and configuration of the $\mathrm{CO}_{2}$-capture unit (e.g, equipment sizes) and amount to 14 in the case of a chemical absorption unit with MEA (Table E.2), 5 in the case of a physical absorption module with MeOH (Table E.3), 5 with DEPG (Table E.4), 6 with TEA (Table E.5). 13 other decision variables (Table E.6) are related to the design of the natural gas pre-processing and of the associated utilities in the $\mathrm{CO}_{2}$ pre-combustion path.

\section{Appendix F. Sensitivity analyses}

The sensitivity analyses of the electricity production (COE) and avoidance (CAC) costs of an offshore platform to different factors such as the $\mathrm{CO}_{2}$-tax are presented as follows.

Oil price. These variations of the oil prices may have an impact on the profitability of waste heat recovery and $\mathrm{CO}_{2}$-capture plants, as these could result in variations of the gas prices. In the case that Norwegian oil and gas producers sign supply agreements based on oil indexation, instead of spot prices, the installation of new equipments will be directly impacted by the oil price fluctuations on the market. Such contracts are agreed on a 15-20 year basis, implying that the profitability of these additional processes will be influenced for more than a half of their lifetime. In the last decade, increasing oil prices pushed towards extended exploitation of oil fields, and the use of $\mathrm{CO}_{2}$ for enhanced oil recovery could therefore be favoured. On the contrary, decreasing oil prices would discourage the use of costly oil recovery techniques, and the integration of CCS processes would be unfavourable without a rise of the carbon taxes.

$\mathrm{CO}_{2}$-tax. Similarly, the taxation on $\mathrm{CO}_{2}$ depends on the industrial sector and country of application: it is at the moment about $\$ 65$ per tonne of $\mathrm{CO}_{2}$ in the Norwegian petroleum sector, and it will most likely rank as one of the highest $\mathrm{CO}_{2}$-taxes in Europe. In Europe, the foreseen values of the $\mathrm{CO}_{2}$-taxes range between $\$ 20$ and $\$ 40$ in the near-future and between $\$ 65$ and $\$ 75$ in the long-term. More precisely, the cost projections suggest that carbon tax prices will rise only moderately in the coming decade, reaching about $\$ 35$ in 2030 , as a consequence of the financial crises and surplus of allowances and international credits. These costs may then increase significantly, up to $\$ 55$ in 2050, to support low-carbon technologies and energy efficiency measures $[45,53]$.

As suggested by the first sensitivity analysis, the $\mathrm{CO}_{2}$-tax also has a strong impact on the electricity and $\mathrm{CO}_{2}$-avoidance costs (Figure F.22). For a natural gas price of $8.08 \$ / \mathrm{GJ}$, which is in the range of the production costs estimated by the oil companies operating petroleum fields in Norway, the break-even values are about 35 and $100 \$ / \mathrm{tCO}_{2}$ for the first and second configurations, respectively. This large difference 
between the break-even values illustrates that the implementation of $\mathrm{CO}_{2}$-capture processes may be feasible or economically profitable only over a certain range of $\mathrm{CO}_{2}$-capture potentials.
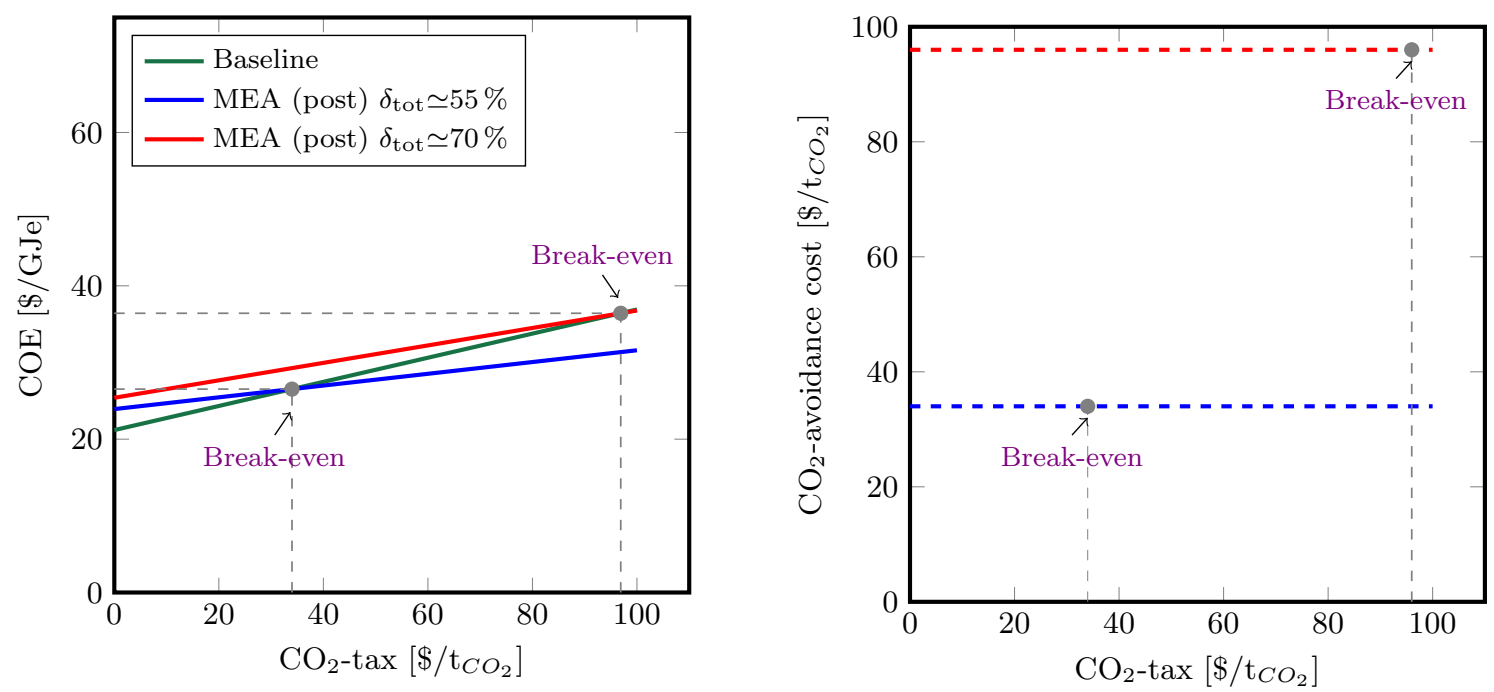

Figure F.22: Sensitivity of the electricity production (COE) and avoidance (CAC) costs of an offshore platform with and without integration of post-combustion $\mathrm{CO}_{2}$-capture to the carbon taxation.

$\mathrm{CO}_{2}$-injection wells. The present work assumes that $\mathrm{CO}_{2}$ could and would be injected into the reservoir for possible enhanced oil recovery or long-term storage. Depending on the field, existing wells may be used if not producing any longer, or new ones may have to be built. In that case, these expenses are site-specific and the cost estimates vary widely from one study to another (Figure F.23). They consist of the costs for building the injection wells, cementing the wells, installing corrosion resistant casing, drilling and constructing the pipelines, and have been estimated to about $15 \mathrm{M} \$$ in the case of the Sleipner platform. The electricity and $\mathrm{CO}_{2}$-avoidance costs of the process configurations with CCS are highly sensitive to the site-specific costs, and those sensitivity analyses suggest that an offshore platform with a high degree of $\mathrm{CO}_{2}$-reduction may only be economically viable, in the future, with a further increase of the $\mathrm{CO}_{2}$-tax, and unlikely for all petroleum fields. The economic profitability of $\mathrm{CO}_{2}$-capture and storage on offshore fields is expected to decrease sharply if $\mathrm{CO}_{2}$ cannot be injected on-site and has to be transported to the shore or to other platforms, as suggested by feasibility studies on that topic.

\section{Appendix G. Environmental impacts}

The benefits of $\mathrm{CO}_{2}$-capture processes combined with steam Rankine cycles can also be drawn with regards to the acidification and eutrophication potentials, as the on-site $\mathrm{NO}_{\mathrm{x}}$ emissions are decreased by about $25 \%$. Although the chemical absorption process induces an energy penalty, the overall natural gas consumption for the platforms on which carbon capture is implemented is decreased, because this results in 

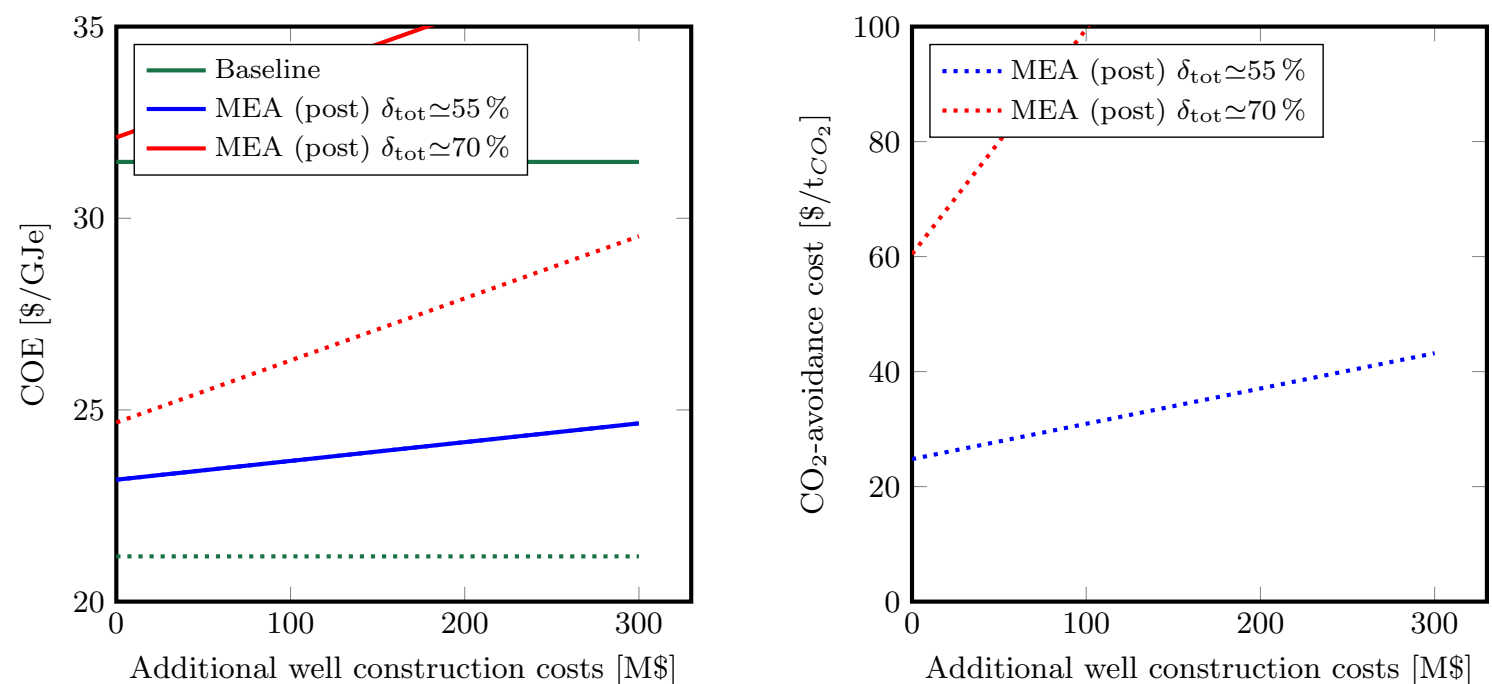

Figure F.23: Sensitivity of the electricity production (COE) and avoidance (CAC) costs of an offshore platform with and without integration of $\mathrm{CO}_{2}$-capture to the additional construction and capital costs.

a smaller depletion of the gas resources. Similarly, the impact on human health is reduced because of the smaller emissions of $\mathrm{CO}_{2}$, nitrous oxides and pollutants, and this is illustrated with both the Ecoindicator 99 [54] and Impact 2002+ methods (Figure G.24 and Figure G.25).

For the climate change impact category, the main contributions are caused by the emissions of fossil $\mathrm{CO}_{2}$ from the gas turbines $(\simeq 85 \%)$. The emissions associated with the manufacturing and installation phases of the system components play the major role $(\simeq 85 \%)$ for the ecosystem impact, and the greatest impact on human health derives from the $\mathrm{NO}_{x}$-emissions $(\simeq 60 \%)$. The same conclusions can be drawn when applying the Ecoindicator 99 approach. One of the main differences is that the climate change impacts are considered within the human health category, and the impact decrease is more marked as it is affected by the reductions of both $\mathrm{CO}_{2}$ and nitrous oxide emissions. 


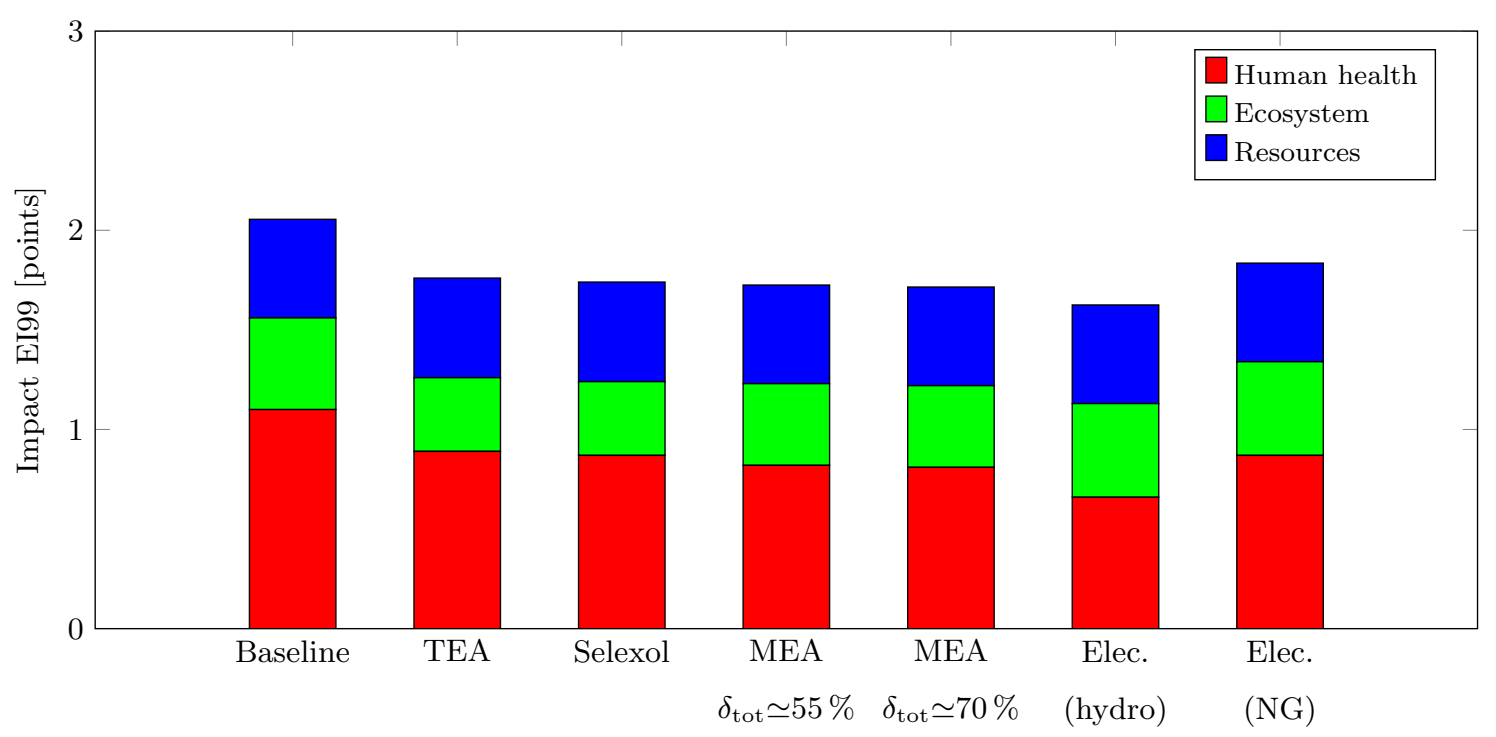

Figure G.24: Comparison of the scenarios with and without $\mathrm{CO}_{2}$-capture: EI99 (hierarchical approach).

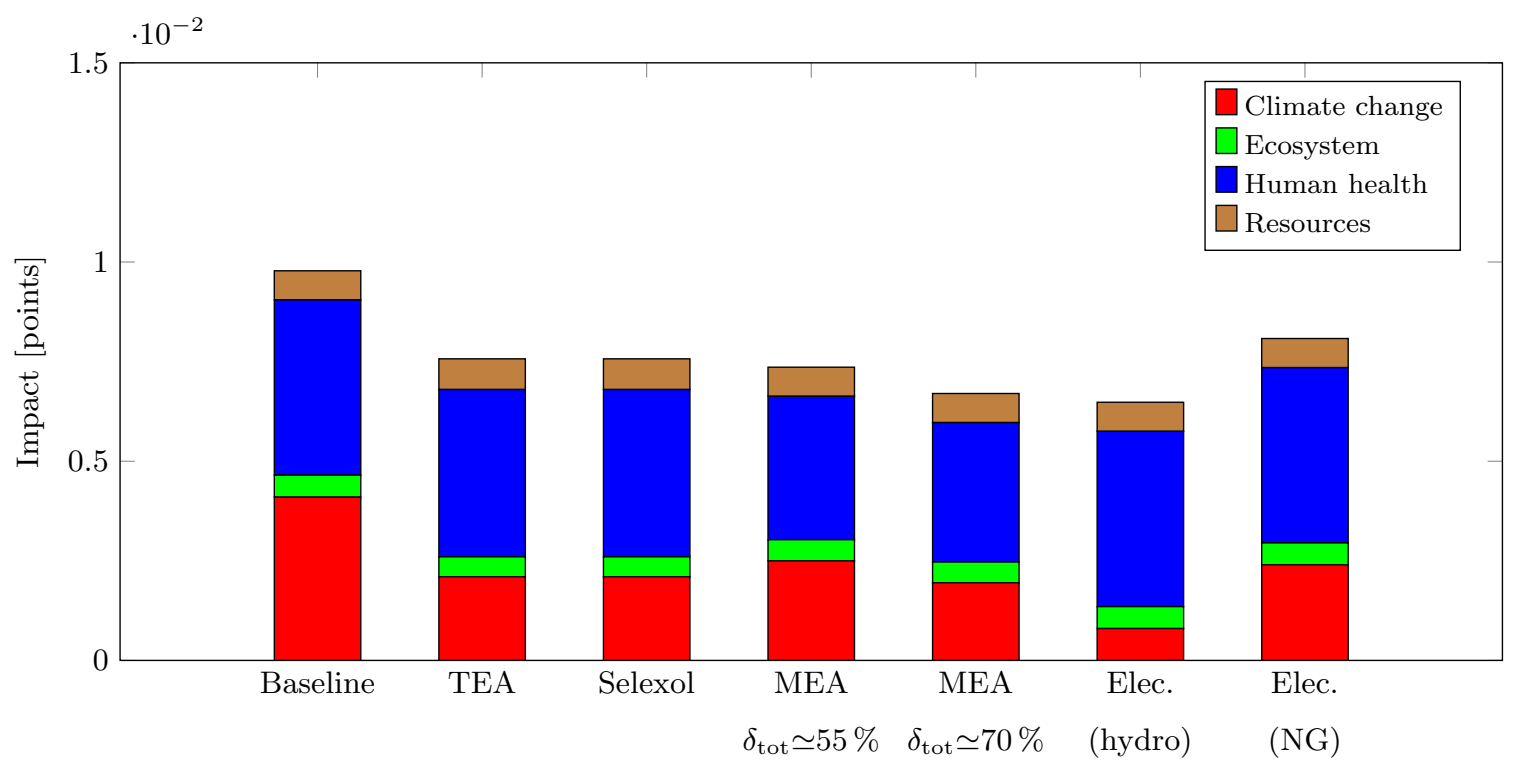

Figure G.25: Comparison of the scenarios with and without $\mathrm{CO}_{2}$-capture: Impact 2002+. 


\begin{tabular}{|c|c|c|c|}
\hline \multicolumn{4}{|c|}{ Nomenclature } \\
\hline \multicolumn{2}{|c|}{ Abbreviations } & $\Delta h^{0}$ & Heating value, $\mathrm{kJ} / \mathrm{kg}$ \\
\hline+ & Material-/Energy-flow entering the system & $\Delta k^{0}$ & Specific exergy, $\mathrm{kJ} / \mathrm{kg}$ \\
\hline - & Material-/Energy-flow leaving the system & $\delta$ & Relative variation, $\%$ \\
\hline $\mathrm{CAC}$ & Carbon avoidance cost & $\eta$ & Energy efficiency, \% \\
\hline $\mathrm{CC}$ & Combined cycle & $\sigma$ & Energy intensity, \% \\
\hline CCS & Carbon capture and storage & $I$ & Environmental impact, $\mathrm{kg} / \mathrm{FU}$ \\
\hline $\mathrm{COE}$ & Cost of electricity & \multicolumn{2}{|c|}{ Roman letters } \\
\hline DNA & Dynamic Network Analysis & $\dot{m}$ & Mass flow, $\mathrm{kg} / \mathrm{s}$ or $\mathrm{t} / \mathrm{h}$ \\
\hline EOS & Equation of State & $\dot{Q}$ & Heat, kW \\
\hline eq & equivalent & $\dot{R}_{k}$ & Residual heat load, $\mathrm{kW}$ \\
\hline FG & Fuel gas & $\dot{W}$ & Work, kW \\
\hline FU & Functional Unit & $\dot{W}_{\text {aux }}^{+}$ & Auxiliary power consumption on-site, $\mathrm{kW}$ \\
\hline GE & Exported gas & $\dot{W}_{\mathrm{g}}^{+}$ & Imported electricity from the grid, $\mathrm{kW}$ \\
\hline GWP & Global Warming Potential & $\dot{W}_{s}^{-}$ & Net power production (reference conditions), $\mathrm{kW}$ \\
\hline IPCC & Intergovernmental Panel on Climate Change & $\dot{W}_{\mathrm{g}}^{-}$ & Exported electricity to the grid, $\mathrm{kW}$ \\
\hline LCA & Life Cycle Assessment & $A$ & Capacity or size parameter \\
\hline LCI & Life Cycle Inventory & $C_{\mathrm{bm}}^{0}$ & Bare module costs, $\$$ \\
\hline MILP & Mixed Integer Linear Programming & $C_{\mathrm{gr}}^{0}$ & Grassroot costs, $\$$ \\
\hline MINLP & Mixed Integer Non-Linear Programming & $C_{\mathrm{op}}$ & Operating costs, $\$$ \\
\hline MOO & Multi-Objective Optimisation & $C_{\mathrm{pc}}$ & Purchased-equipment costs, $\$$ \\
\hline MSI & Marshall Swift Index & $c_{e^{+}}$ & Purchase price of electricity, $\$ / \mathrm{kW}$ \\
\hline NG & Natural gas & $c_{e^{-}}$ & Sales price of electricity, $\$ / \mathrm{kW}$ \\
\hline $\mathrm{OE}$ & Exported oil & $f_{m}$ & Material factor (bare module costs) \\
\hline ORC & Organic Rankine cycle & $f_{p}$ & Pressure factor (bare module costs) \\
\hline PR & Peng-Robinson & $f_{s}$ & Level of utilisation of a process or sub-system \\
\hline ref & reference & $N_{k}$ & Number of temperature intervals \\
\hline $\mathrm{SRC}$ & Steam Rankine cycle & $N_{s}$ & Number of subsystems, processes and utilities \\
\hline Greek le & tters & $p$ & Pressure, bar \\
\hline$\alpha_{1}$ & Contingencies factor (grassroot costs) & $T$ & Temperature, ${ }^{\circ} \mathrm{C}$ or $\mathrm{K}$ \\
\hline$\alpha_{2}$ & Auxiliary factor (grassroot costs) & $T^{*}$ & Corrected temperature, ${ }^{\circ} \mathrm{C}$ or $\mathrm{K}$ \\
\hline
\end{tabular}


Table E.2: Set of the master decision variables used in the multi-objective optimisation of the $\mathrm{CO}_{2}$-capture unit based on chemical absorption with an aqueous solution of monoethanolamine.

\begin{tabular}{lllr}
\hline Variable & Type & Unit & Range \\
\hline Lean solvent $\mathrm{CO}_{2}$ loading & continuous & kmol/kmol & {$[0.18-0.25]$} \\
Rich solvent $\mathrm{CO}_{2}$ loading & continuous & $\mathrm{kmol} / \mathrm{kmol}$ & {$[0.4-0.5]$} \\
Split fraction & continuous & - & {$[0 ; 1]$} \\
Rich solvent preheat temperature & continuous & ${ }^{\circ} \mathrm{C}$ & {$[95-105]$} \\
Rich solvent reheat temperature & continuous & ${ }^{\circ} \mathrm{C}$ & {$[115-125]$} \\
LP stripper pressure & continuous & bar & {$[1.7-2.1]$} \\
HP/LP pressure ratio & continuous & - & {$[1-1.5]$} \\
Number stages absorber & continuous & - & {$[10-17]$} \\
Number stages HP stripper & continuous & - & {$[8-15]$} \\
Number stages LP stripper & continuous & - & {$[6-10]$} \\
Absorber diameter & continuous & $\mathrm{m}$ & {$[6-12]$} \\
LP stripper diameter & continuous & $\mathrm{m}$ & {$[2-5]$} \\
HP stripper diameter & continuous & $\mathrm{m}$ & {$[3-6]$} \\
MEA concentration (solvent) & continuous & wt \% & {$[30-40]$} \\
\hline
\end{tabular}

Table E.3: Set of the master decision variables used in the multi-objective optimisation of the $\mathrm{CO}_{2}$-capture unit based on physical absorption with methanol.

\begin{tabular}{lllr}
\hline Variable & Type & Unit & Range \\
\hline MeOH $/ \mathrm{CO}_{2}$ ratio & continuous & $\mathrm{kmol} / \mathrm{kmol}$ & {$[10-15]$} \\
Absorber temperature & continuous & ${ }^{\circ} \mathrm{C}$ & {$[-70-0]$} \\
Absorber pressure & continuous & bar & {$[15-60]$} \\
Regenerator pressure & continuous & bar & {$[1-10]$} \\
Regenerator temperature & continuous & ${ }^{\circ} \mathrm{C}$ & {$[20-100]$} \\
\hline
\end{tabular}

Table E.4: Set of the master decision variables used in the multi-objective optimisation of the $\mathrm{CO}_{2}$-capture unit based on physical absorption with DEPG.

\begin{tabular}{lllr}
\hline Variable & Type & Unit & Range \\
\hline DEPG/ $\mathrm{CO}_{2}$ ratio & continuous & $\mathrm{kg} / \mathrm{kg}$ & {$[8-14]$} \\
Absorber temperature & continuous & ${ }^{\circ} \mathrm{C}$ & {$[-18-173]$} \\
Absorber pressure & continuous & bar & {$[10-60]$} \\
Regenerator pressure & continuous & bar & {$[1-10]$} \\
Regenerator temperature & continuous & ${ }^{\circ} \mathrm{C}$ & {$[25-100]$} \\
\hline
\end{tabular}


Table E.5: Set of the master decision variables used in the multi-objective optimisation of the $\mathrm{CO}_{2}$-capture unit based on chemical absorption with an aqueous solution of TEA.

\begin{tabular}{lllr}
\hline Variable & Type & Unit & Range \\
\hline TEA concentration & continuous & $\mathrm{kg} / \mathrm{kg}$ & {$[0.25-0.40]$} \\
$\mathrm{H}_{2}$-TEA ratio & continuous & $\mathrm{kg} / \mathrm{kg}$ & {$[0.035-0.055]$} \\
Absorber temperature & continuous & ${ }^{\circ} \mathrm{C}$ & {$[20-45]$} \\
Absorber pressure & continuous & bar & {$[15-30]$} \\
Regeneration pressure & continuous & bar & {$[1-130]$} \\
Regeneration temperature & continuous & ${ }^{\circ} \mathrm{C}$ & {$[25-120]$} \\
\hline
\end{tabular}

Table E.6: Set of the master decision variables used in the multi-objective optimisation of the pre-combustion $\mathrm{CO}_{2}$-capture path.

\begin{tabular}{lllr}
\hline Variable & Type & Unit & Range \\
\hline SMR temperature & continuous & \multicolumn{1}{c}{${ }^{\circ} \mathrm{C}$} & {$[450-950]$} \\
ATR temperature & continuous & ${ }^{\circ} \mathrm{C}$ & {$[500-950]$} \\
Reforming pressure & continuous & bar & {$[1-30]$} \\
Air-to-carbon ratio (ATR) & continuous & $\mathrm{kg} / \mathrm{kg}$ & {$[3-4.5]$} \\
Steam-to-carbon ratio (ATR) & continuous & $\mathrm{kg} / \mathrm{kg}$ & {$[1.5-6]$} \\
High-temperature water-gas-shift & continuous & ${ }^{\circ} \mathrm{C}$ & {$[250-420]$} \\
Low-temperature water-gas-shift & continuous & ${ }^{\circ} \mathrm{C}$ & {$[150-250]$} \\
Water-gas-shift pressure & continuous & $\mathrm{bar}$ & {$[1-30]$} \\
CO ${ }_{2}$-capture unit & discrete & - & $\{0-3\}$ \\
Oxygen-to-hydrogen ratio & continuous & $\mathrm{kmol} / \mathrm{kmol}$ & {$[0.4-0.7]$} \\
$\mathrm{H}_{2}$-turbine combustion pressure & continuous & bar & {$[5-50]$} \\
Exhaust gas temperature & continuous & ${ }^{\circ} \mathrm{C}$ & {$[100-200]$} \\
Low-pressure level (refrigeration cycle) & continuous & bar & {$[0.1-5]$} \\
\hline
\end{tabular}

